\title{
Policy Pathways to Meet Saudi Arabia's Contributions to the Paris Agreement
}

David Wogan, Elizabeth Carey and Douglas Cooke 


\section{About KAPSARC}

The King Abdullah Petroleum Studies and Research Center (KAPSARC) is a non-profit global institution dedicated to independent research into energy economics, policy, technology and the environment across all types of energy. KAPSARC's mandate is to advance the understanding of energy challenges and opportunities facing the world today and tomorrow, through unbiased, independent, and high-caliber research for the benefit of society. KAPSARC is located in Riyadh, Saudi Arabia.

\section{Legal Notice}

(C) Copyright 2019 King Abdullah Petroleum Studies and Research Center (KAPSARC). No portion of this document may be reproduced or utilized without the proper attribution to KAPSARC. 


\section{Key Points}

audi Arabia developed its first nationally determined contribution (NDC) under the Paris Agreement that included its carbon mitigation goals through 2030. This paper evaluates several policy approaches to

mitigate carbon dioxide $\left(\mathrm{CO}_{2}\right)$ emissions from the power and water sectors which, combined, contribute over $40 \%$ of the country's greenhouse gas emissions. These approaches build on existing efforts to expand non-fossil electricity production and energy sector reform as part of Saudi Vision 2030.

This study examines the practical implications of these policy approaches on $\mathrm{CO}_{2}$ emissions, electricity production, fuel consumption, investments and cost-effectiveness, as well as on oil exports and revenues. In addition to a business as usual (BAU) scenario, four alternative scenarios were analyzed:

A Portfolio Standard (PS) requiring up to 50 gigawatts (GW) of solar, wind and nuclear technology deployment.

A Clean Energy Standard (CES) that simulates a package of notional policies that reduce the carbon intensity of electricity production.

A Partial Fuel Price Reform (FPRp) where fuel prices are raised to half of international levels gradually to 2030.

A Full Fuel Price Reform (FPRf) where prices are raised to international levels starting in 2018.

Figure 1. Emissions reduction pathways.

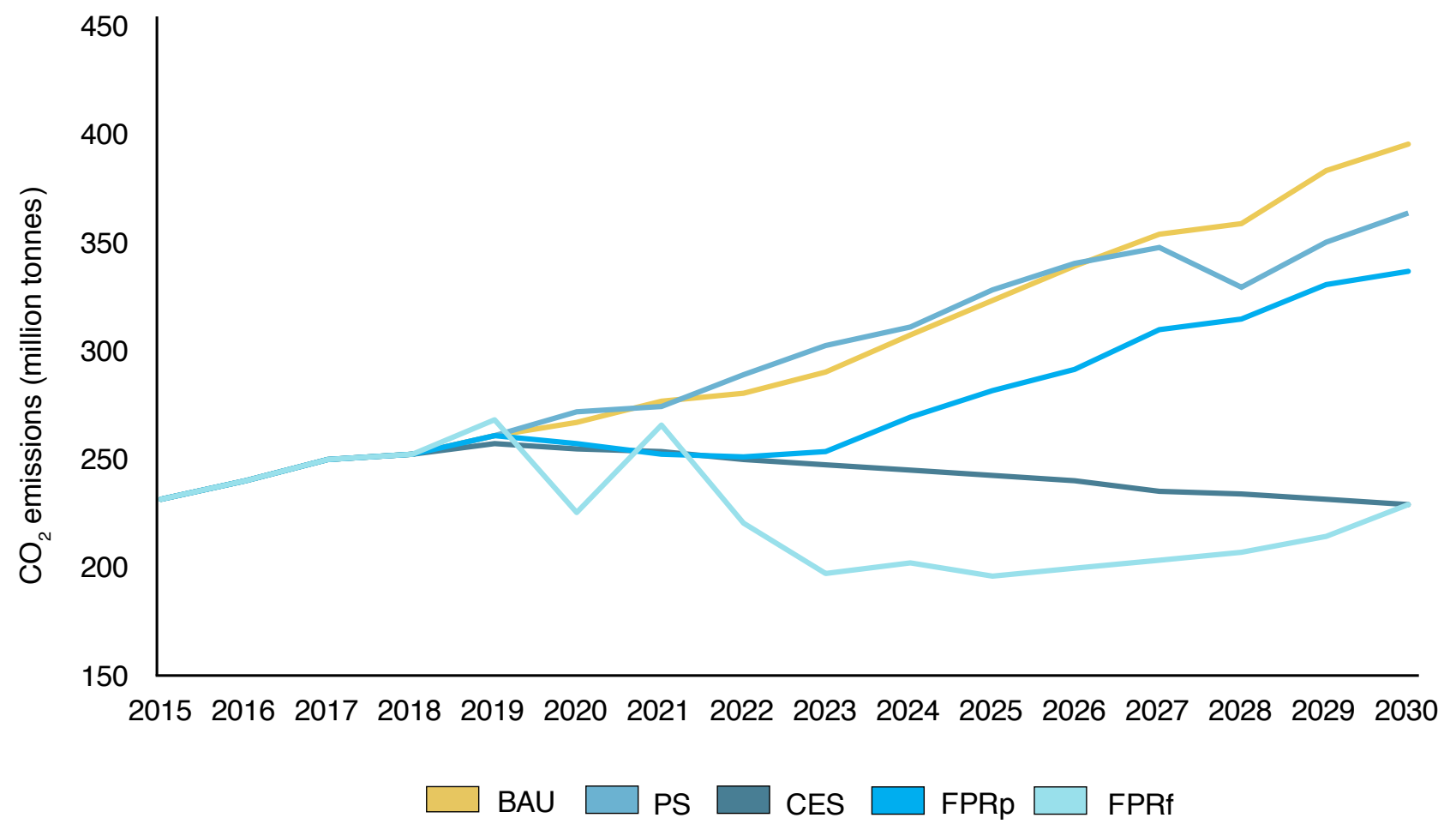

Source: KAPSARC analysis. 
Rationalizing costs of fuel inputs is critical to driving large $\mathrm{CO}_{2}$ emissions reductions and providing a net economic benefit to the Saudi Arabian economy. Fully deregulating fuel prices delivers the largest $\mathrm{CO}_{2}$ emissions reductions of the scenarios considered in this study (1.2 billion tonnes cumulative through 2030) while also providing a $\$ 911$ billion net economic benefit. In this policy scenario, the power system supplies electricity demand through natural gas-fired combined cycle gas turbines (64\%) and solar photovoltaic (PV) generation (20\%).

A Clean Energy Standard designed to achieve similar reductions could also deliver a positive net economic benefit of $\$ 394$ billion. While deep $\mathrm{CO}_{2}$ cuts can be achieved, oil would still be consumed for domestic power production, which would reduce revenues from oil exports and lower gains from fuel savings. This policy scenario has the benefit of placing a ceiling on emissions while allowing for flexibility to choose the most cost-effective technologies, rather than mandating technologies (e.g., requiring generation from nuclear or solar PV regardless of economics). The specific design of a CES and its pathway will influence the schedule of investments. Therefore, the estimated costs and benefits presented in this paper are more illustrative of the concept.

A Portfolio Standard is not necessarily an effective policy to reduce $\mathrm{CO}_{2}$ emissions. In this analysis, only modest $\mathrm{CO}_{2}$ emissions cuts were observed, despite the deployment of nearly $50 \mathrm{GW}$ of solar PV. Such a policy would need to be designed with the short-run marginal costs (fuel substitution) and long-run marginal costs (technology investment) to achieve deeper $\mathrm{CO}_{2}$ emissions reductions.

Among other issues, these insights highlight the potential risks associated with implementing climateoriented policies in the power sector in the presence of regulated fuel prices. A more effective policy approach in the Saudi Arabian context would seek to fully deregulate fuel prices before proceeding with subsequent policy interventions to reduce carbon emissions in the power and water sectors. Full deregulation would help to avoid unintended consequences and compounding existing distortions in the economy. The results show that several potential opportunities exist for Saudi Arabia to capitalize on its energy diversification strategy to help deliver substantial $\mathrm{CO}_{2}$ emissions reductions consistent with achieving its carbon abatement goals. 


\section{Summary}

$\mathbf{T}$ The 2015 Paris Agreement fundamentally altered the nature of global cooperation to address climate change and its impacts. Consistent with the Paris approach, Saudi Arabia developed its first nationally determined contribution (NDC) to reflect the challenges and opportunities it faces as one of the world's leading suppliers of crude oil in an increasingly carbonconstrained world. The Kingdom's NDC aims to support and accelerate the reform of its economy while delivering carbon mitigation co-benefits. The initial NDC aspires to avoid up to 130 million tonnes of $\mathrm{CO}_{2}$-equivalent $\left(\mathrm{CO}_{2} \mathrm{e}\right)$ emissions per annum by 2030 through economic diversification and adaptation.

This study evaluates a suite of supply side mitigation policy approaches relevant to Saudi Arabia, with the aim of supporting the policymaking process ahead of the communication by the Kingdom of its second NDC in 2020. This study focuses on the power and water sectors, the largest sources of carbon emissions, which, combined, represented around $40 \%$ of Saudi Arabia's carbon emissions in 2014. The study covers the period 2015 through 2030.

This paper finds that a continuation of current policies would increase power sector emissions in 2030 by $70 \%$ over 2015 levels. Rationalizing costs of fuel inputs is critical to driving large $\mathrm{CO}_{2}$ emissions reductions and providing a net economic benefit to the Saudi Arabian economy. Fully deregulating fuel prices delivers the largest $\mathrm{CO}_{2}$ emissions reductions of the scenarios considered in this study (1.2 billion tonnes cumulative through 2030) while also providing a $\$ 911$ billion net economic benefit. In this policy scenario, the power system supplies electricity demand primarily through natural gas-fired combined cycle gas turbines (CCGTs) (64\%) and solar photovoltaic (PV) generation (20\%).

A Clean Energy Standard (CES) designed to achieve similar reductions could also deliver a positive net economic benefit of $\$ 394$ billion. While deep $\mathrm{CO}_{2}$ cuts can be achieved, oil was still consumed for domestic power production which reduced revenues from oil exports. The CES also had the effect of lowering fuel costs. This policy scenario has the benefit of placing a ceiling on emissions while allowing for flexibility to choose the most cost-effective technologies, rather than mandating technologies (e.g., requiring generation from nuclear or PV regardless of the economics). The specific design of a CES and its pathway will influence the schedule of investments. Therefore, the estimated costs and benefits presented in this paper are more illustrative of the concept.

\section{A Portfolio Standard (PS) is not necessarily an} effective policy to reduce $\mathrm{CO}_{2}$ emissions. In this analysis, only modest $\mathrm{CO}_{2}$ emissions cuts were observed despite the deployment of nearly 50 gigawatts (GW) of solar PV. Such a policy would need to be designed with short-run marginal costs (fuel substitution) and long-run marginal costs (technology investment) to achieve deeper $\mathrm{CO}_{2}$ emissions reductions.

Increased revenue from oil exports and domestic sales of higher priced fuels to the power and water sectors could offset the mitigation costs by being redistributed to other sectors of the economy. This paper does not explicitly model redistributional impacts but estimates that full fuel price deregulation would deliver the largest incremental economic gain by eliminating the opportunity cost of subsidized fuel consumption. 
$\mathrm{T}$ The adoption of the Paris Agreement in December 2015 introduced a new model of global governance that radically transformed the nature of the collective effort to address climate change. Based on a system of nationally determined contributions (NDCs), the Agreement represents a fundamental departure from the top down 'onesize-fits-all' policy prescriptions of the past, in favor of a decentralized approach which incorporates national carbon mitigation goal-setting into a global framework to drive collective action. Crucially, this new approach recognizes that each country's policy response to climate change must reflect its unique economic, resource and development conditions. It marks a clear break from the Kyoto Protocol and its top-down, legally binding, quantified emissions reductions targets that covered only a fraction of global greenhouse gases (GHGs) emissions, estimated at around $14 \%$ in its second commitment period (Erbach 2015).

The Agreement that resulted from this more flexible approach garnered the support of 195 countries covering virtually the world's entire GHG emissions. Its strength lies in its combination of legally binding and non-legally binding provisions, as reflected in the NDCs. While each country is free to determine the nature and extent of its contribution, countries are obligated to submit a contribution every five years, with each successive NDC expected to be more ambitious. Saudi Arabia communicated its intended nationally determined contribution (INDC) under the Paris Agreement in November 2015, which subsequently became the Kingdom's first NDC after the Kingdom ratified the Agreement on Nov. 3, 2016.

The Paris Agreement sets the direction of travel in an increasingly carbon-constrained world, with potentially fundamental implications for the Kingdom as one of the world's top oil producers and exporters. Within this context, the Kingdom of Saudi Arabia is pursuing a strategy of economic diversification, as set out in Vision 2030, to reduce its reliance on oil export revenues. Its NDC is designed to support and accelerate this strategy. As expressed in the NDC's best-case scenario (Scenario 1 of a pathway of sustained economic growth), economic diversification is expected to contribute to delivering mitigation co-benefits by avoiding of up to 130 million tonnes of $\mathrm{CO}_{2}$ equivalent $\left(\mathrm{CO}_{2} \mathrm{e}\right)$ per annum by 2030 (UNFCCC 2015).

In determining its current and future contributions under the Paris Agreement, the Kingdom faces multiple levels of uncertainty. At a global level, the nature and pace of decarbonization remain uncertain. At a domestic level, future economic pathways for the Kingdom are also uncertain. This uncertainty is reflected in the two scenarios of the NDC which incorporate a dynamic baseline reflecting two different views of the Kingdom's economic future: economic diversification (Scenario 1, which delivers mitigation co-benefits) and accelerated industrialization (Scenario 2, which does not deliver mitigation co-benefits). These uncertainties underscore the importance of exploring pathways for how the Kingdom can pursue its NDC goals under the Paris Agreement.

This paper is intended to inform the policymaking process and the development of future iterations of the Kingdom's NDC. It focuses on three policy approaches for the power and water desalination sectors, which, combined, is the single largest source of $\mathrm{CO}_{2}$ emissions in the Saudi economy. The implementation period for these scenarios starts in 2018 and runs through 2030. This paper examines the practical implications of these approaches on $\mathrm{CO}_{2}$ emissions, electricity production, fuel consumption, investments and cost-effectiveness, as well as on oil exports and revenues. 


\section{The Paris Agreement}

The Paris Agreement was adopted at the 21st session of the Conference of the Parties to the United Nations Framework Convention on Climate Change (UNFCCC ) in December 2015 and came into force on Nov. 4, 2016 (UNFCCC 2015). At present, 184 Parties have ratified the Agreement which falls under the UNFCCC or Convention, adopted at the Rio Summit in 1992 by 197 signatory Parties (UNFCCC 1992, 2018).

It marks a shift away from the highly prescriptive and centrally determined emissions reduction targets of the Kyoto Protocol, toward a more flexible, decentralized system based on NDCs (UNFCCC 1998). These NDCs lie at the heart of the Paris Agreement and contain countries' voluntary contributions regarding both mitigation and adaptation.

The Paris Agreement and the NDCs correspond to a new paradigm that reflects the priorities and socio-economic conditions of each country, their resource endowment, the nature and extent of their vulnerability to the impacts of climate change, and their status as a developed, developing or least developed country, or small island developing state. The Agreement reaffirms the UNFCCC's principle of common but differentiated responsibilities and respective capabilities (the CBDR-RC principle), while introducing a greater degree of flexibility "in the light of different national circumstances" (Article 2.2, see Appendix A). In addition, while countries are not legally bound to fulfill the objectives and targets outlined in their NDCs, they are obligated to communicate an NDC to the UNFCCC Secretariat every five years. Each submission is expected to represent a progression compared with the previous one and to reflect the respective country's highest level of ambition (Article 4, see Appendix B).

The absence of any reference to Annex I or non-Annex I Parties throughout the text of the Agreement reflects this change of paradigm. There is no longer a rigid distinction between different categories of countries. This distinction had become increasingly difficult to justify, given the rapid rise of several industrializing countries that are collectively responsible for a substantial and growing share of global GHG emissions. Differentiation between countries now essentially lies within the NDCs themselves, with signatory Parties free to determine their own objectives, targets and baselines. This flexibility, combined with a more transparent compliance mechanism, has the potential to facilitate a more effective implementation of the Agreement (Articles 13, 14, 15, see Appendix B).

\section{Saudi Arabia's nationally determined contribution}

Saudi Arabia communicated its INDC to the UNFCCC Secretariat on Nov. 15, 2015, within this context of a new, adaptable, global climate governance framework (UNFCCC 2015), and ratified the Paris Agreement on Nov. 3, 2016. Its INDC thereby became its first NDC (UNFCCC 2018).

Saudi Arabia's NDC is designed to support and accelerate the Kingdom's policy of diversification away from an economy highly dependent on hydrocarbons. The petroleum sector currently accounts for about $50 \%$ of gross domestic product (GDP) and about $70 \%$ of export earnings (OPEC 2018). The Kingdom aims to implement measures that will accelerate its path toward economic diversification and generate mitigation co-benefits. This is consistent with Article 4.7 of the Agreement 


\section{Saudi Arabia's NDC under the Paris Agreement}

Saudi Arabia's NDC is based on a dynamic baseline representing a combination of two scenarios:

Scenario 1: Robust oil export revenues in support of an increasingly diversified economy.

Scenario 2: Domestic utilization of oil and gas in support of accelerated domestic industrialization.

Scenario 1 would allow for the avoidance of up to 130 million tonnes of $\mathrm{CO}_{2} \mathrm{e}$ annually by 2030 compared to a business-as-usual scenario. The baseline assessment period is 2021-2030, to be extended over time to 2050. The overarching timeframe of the scenarios (2000-2030) is divided into three periods (2000-2015, 2016-2020 and 2021-2030).

The measures presented in the NDC include the following:

1. Economic diversification with mitigation co-benefits:

- Energy efficiency measures

- Renewable energies

- Carbon capture and utilization/storage (with a $\mathrm{CO}_{2}$-enhanced oil recovery demonstration project at Othmaniya)

- Greater utilization of gas

- Methane recovery and flare minimization

2. Adaptation measures with mitigation co-benefits:

-Water and wastewater management

- Urban planning

- Marine protection

- Reduced desertification

3. Other adaptation measures:

- Integrated coastal zone management planning for the protection of coastal infrastructure (such as roads, residential areas, industrial complexes, desalination plants and seaports)

- Early warning systems to reduce vulnerability due to extreme weather events

- Integrated water management planning

The Kingdom is developing a monitoring, reporting and verification (MRV) system for its NDC under the oversight of its Designated National Authority. 
which acknowledges the potential for mitigation co-benefits resulting from Parties' adaptation actions and/or economic diversification plans (see Appendix B).

Specifically, the Kingdom seeks to achieve mitigation co-benefits by avoiding up to 130 million tonnes of $\mathrm{CO}_{2}$ e per annum by 2030 through economic diversification and adaptation measures with mitigation co-benefits. The mitigation potential of the measures presented in the NDC would prevent 'lock-in' of high GHG emitting infrastructure.

With this objective in mind, the NDC is built on a dynamic baseline reflecting a combination of two scenarios that correspond to two different future economic pathways:

Scenario 1 is based on economic diversification, with revenues derived from oil exports invested into high value-added sectors such as financial services, medical services, tourism, education, renewable energy and energy efficiency technologies, to help diversify the economy.

Scenario 2 is based on accelerated domestic industrialization in which domestic oil resources are used as feedstock to build a heavy industrial base. In this scenario, the petrochemical, cement, mining and metal production industries will make increasing contributions to the national economy.

The difference between the two scenarios lies in the allocation of oil either for exports (Scenario 1) or domestic consumption (Scenario 2). In Scenario 1 , oil revenues derived from exports fund economic growth and diversification; it avoids up to 130 million tonnes of $\mathrm{CO}_{2}$ e per annum by 2030. By contrast, economic growth under Scenario 2 is assumed to be much slower than in Scenario 1, largely due to lower oil export revenues. Scenario
2 would not fulfill the NDC's ambition to avoid up to 130 million tonnes of $\mathrm{CO}_{2}$ e because growing domestic consumption of oil would increase the Kingdom's GHG emissions. In this case, the Kingdom will adjust its NDC to account for this scenario. The baseline scenarios will be updated over the validity period of the NDC (2016-2020).

\section{Saudi Arabia's $\mathrm{CO}_{2}$ emissions}

Between 1990 and 2014, Saudi Arabia's primary energy consumption increased by a compound annual growth rate of $4.6 \%$ - more than double the world average of 1.9\% (BP 2017). Over the same period, total Saudi Arabian $\mathrm{CO}_{2}$ e emissions increased threefold, from 200 million tonnes in 1990 to around 600 million tonnes in 2014 (Figure 2). The manufacturing and industrial sectors have led emissions' growth rates, at $6 \%$ and $7 \%$, respectively.

Saudi Arabia's carbon emissions are expected to continue to rise in the coming decades. Expanding energy-intensive industries and rapidly increasing demand for power and water is driving emissions growth. Strong population growth, from around four million people in 1960 to over 32 million in 2016, has driven the rapid increase in power and water consumption to date and is expected to continue to do so (Kingdom of Saudi Arabia GaStat 2018).

The power and water sectors ("Electricity" in Figure 3) represent the single largest $\mathrm{CO}_{2}$ source in the economy, at 40\% in 2014 (WRI 2015).

This paper's analysis focuses on policy approaches that can reduce $\mathrm{CO}_{2}$ emissions from the power and water sectors, reflecting the importance of these sectors in meeting the Kingdom's carbon abatement goals. 
Figure 2. Saudi Arabian $\mathrm{CO}_{2}$ e emissions by sector, 1990-2014.

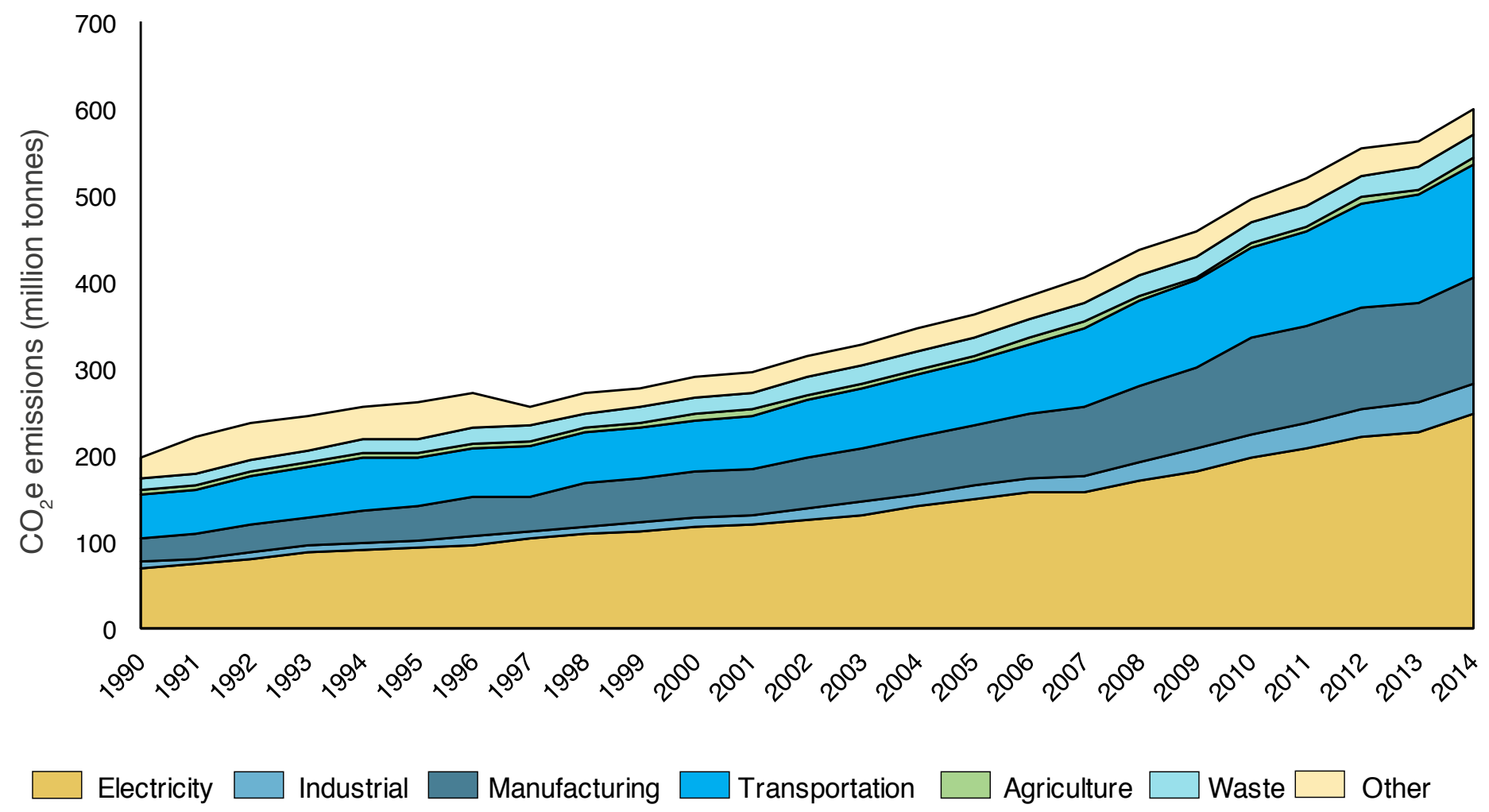

Source: WRI CAIT Climate Data Explorer, KAPSARC analysis.

Figure 3. Share of $\mathrm{CO}_{2}$ e emissions in Saudi Arabia by sector in 2014.

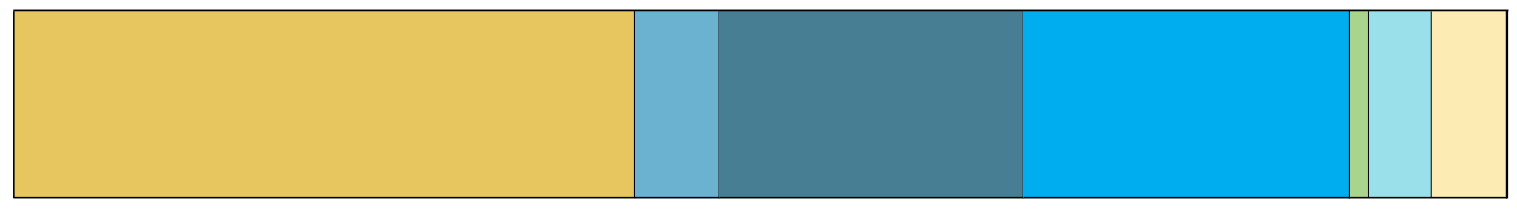

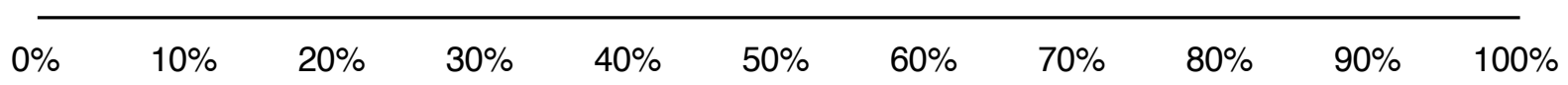

Electricity $\square$ Industrial $\square$ Manufacturing $\square$ Transportation $\square$ Agriculture $\square$ Waste $\square$ Other 


\section{Policy Approaches}

he study considered three broad policy approaches that could be applied to the power and water sectors through to 2030 : a portfolio standard, a clean energy standard, and fuel price reforms. These three alternative policy approaches were assessed against a baseline of continuing existing policies set out in the BAU scenario. Each of these approaches was evaluated in terms of its implications for investment and technology deployment, electricity supply, fuel mix, carbon emissions and cost-effectiveness.

\section{Business as usual}

This study included the government's announced targets for the deployment of low-carbon generating capacity in its 2015 BAU scenario.

The targets announced at the time of our analysis include 9.5 gigawatts (GW) of renewable generation by 2023, including 3.45 GW by 2020 ; a doubling of gas production to 25 billion cubic feet per day by 2023; and $17.6 \mathrm{GW}$ of nuclear capacity by 2032 , starting with a deployment of up to 2.8 GW (Kingdom of Saudi Arabia Vision 2030, 2016; Oil \& Gas Journal 2016).

These capacity deployments were implemented across each of the three policy scenarios. A more detailed description of the policy scenarios follows. The previously implemented industrial fuel price increases for 2015 and 2016 are incorporated. As of publication, fuel prices have not been increased since 2016. Table 1 details the regulated prices of crude oil, natural gas, heavy fuel oil (HFO), and diesel. No further price increases occur in the BAU scenario.

\section{Portfolio standard}

This study first considered a portfolio standard to diversify the technology mix through the deployment of low-carbon generation. Examples of this kind of mandated deployment of low-carbon capacity include China's 13th Renewable Energy Development Five-Year Plan (2016-2020), with a target of $680 \mathrm{GW}$ of installed renewable power capacity by 2020 and a $20 \%$ share of non-fossil energy in total primary consumption by 2030 (Ferroukh et al. 2016). In the United States, 29 of 50 states have adopted renewable portfolio standards (RPS), which can be expressed in terms of installed capacity or power generated. RPSs place an obligation on electricity supply companies to produce a certain minimum share of their electricity from designated renewable energy sources (EIA 2012).

Table 1. Regulated industrial fuel prices in Saudi Arabia in 2015 and 2016.

\begin{tabular}{l|l|l} 
Fuel & 2015 & 2016 \\
\hline Crude oil $(\$ / \mathrm{bbl})$ & 4.24 & 6.35 \\
\hline Natural gas $(\$ / M M B t u)$ & 0.75 & 1.25 \\
\hline HFO $(\$ / \mathrm{bbl})$ & 2.26 & 4.25 \\
\hline Diesel $(\$ / \mathrm{bbl})$ & 3.75 & 14.00
\end{tabular}

Source: Matar 2015, 2017. 
In the Gulf Cooperation Council (GCC) region, Abu Dhabi has set a target of $7 \%$ renewable energy generation capacity by 2020 , which is expected to be met by a combination of solar PV and concentrated solar power (CSP), wind, and waste-to-energy projects. The 100 megawatt (MW) CSP, Shams 1 project opened in March 2013 was the first major project under this initiative. Project-specific tariffs are established following competitive international tendering. Dubai has a target to generate $7 \%$ of its energy from clean energy sources by 2020 , rising to $25 \%$ by 2030 and $57 \%$ by 2050 . Under the Dubai Clean Energy Strategy 2050, solar energy will account for $25 \%$ of the emirate's energy supply requirements, nuclear $7 \%$, clean coal $7 \%$ and gas $61 \%$ by 2030 , with an extended goal to increase solar to $75 \%$ by 2050 (Government of Dubai 2016; Wogan et al. 2017).

This study constructed a notional portfolio standard that feeds directly into the Kingdom's strategy of economic diversification and the introduction of new, low-carbon sources of energy through mandated targets. It corresponds to Scenario 1 of the NDC, which aims to free-up domestically consumed oil for export to fund diversification while achieving mitigation co-benefits. This approach requires adding $30 \mathrm{GW}$ of renewables or nuclear capacity by 2025 and $48 \mathrm{GW}$ by 2030 . These deployments include the targets for renewable and nuclear from the BAU scenario at the time of our analysis (9.5 GW of renewable generation and $17.6 \mathrm{GW}$ of nuclear capacity), and retain existing regulated fuel prices.

\section{Clean energy standard}

This study considered a regulatory response that limits the carbon intensity of economic activity, with carbon intensity defined as the quantity of carbon emitted per unit of electricity produced in tonnes $\mathrm{CO}_{2}$ per terawatthour (TWh). The analysis used a stylized representation, i.e., a set of policies that reduced the overall carbon intensity of the power and water sectors in the Saudi Arabian economy. It explored how a set of notional policies would, in aggregate, create incentives for investment in more efficient generation and optimal fuel use that translates to less carbon-intensive electricity and water production. The model was constructed using the delivered $\mathrm{CO}_{2}$ emission reductions from baseline, illustrated in Figure 7, assuming a combination of notional measures. Crucially, it retains the existing regulated fuel prices.

\section{Fuel pricing reforms}

Saudi Arabia is reforming its electricity sector in order to meet rising power demand, reduce its expenditure on energy subsidies and diversify its economy, in support of the objectives of Vision 2030 and the National Transformation Program (Kingdom of Saudi Arabia Vision 2030, 2016). The Kingdom's objective is to move away from a system based on regulated fuel prices to a system with fuel prices more closely aligned with international prices, through a series of fuel price reforms.

The Kingdom introduced its first set of fuel price increases at the end of 2015 (see Table 1). With prices still well below international benchmarks, Saudi Arabia's 2018 budget set targets for the gradual alignment of domestic fuel prices with international prices by 2025 . In January 2018 , all electricity prices except for industry and government were raised. At the same time, local gasoline prices rose by $126 \%$ for 95 octane and by $82 \%$ for 91 octane (Mohammed 2018; IEA 2018; Minocha 2018).

The scenario for fuel price reforms (FPR) presented in this paper analyzed the climate impacts of fuel price deregulation for two implementation 


\section{Clean Energy Standards in Practice}

\section{The United Kingdom's Emissions Performance Standard}

The Emissions Performance Standard (EPS) was introduced in the United Kingdom as an element of its Electricity Market Reform (EMR) and became law as part of the Energy Act 2013. It provides a regulatory backstop to limit the amount of emissions that can be emitted by new fossil-fuel power stations. The EPS level was set at 450 grams per kilowatthour for all new fossil fuel power stations at or over $50 \mathrm{MW}$, operating at baseload. It was the first of its kind to be introduced by any country of the European Union (EU) (Department of Energy and Climate Change 2013, 2014).

\section{The European Union's Industrial Emissions Directive (integrated pollution and prevention control)}

Directive 2010/75/EU of the European Parliament and the Council on industrial emissions is the EU's main instrument for regulating pollutant emissions from industrial installations. Adopted in November 2010, it entered into force in January 2011.

The Industrial Emissions Directive (IED) is a recast of seven directives. Around 50,000 installations undertaking industrial activities listed in Annex I of the IED are to operate in accordance with a permit. The directive is based on seven pillars that include an integrated approach (permits must consider the entire environmental performance of a plant, best available techniques (BAT), flexibility, mandatory environment inspections and the public's right to participate in the decision-making process). Stricter EU-wide standards were adopted in April 2017, further strengthening the role of cleaner technologies (European Commission 2016, 2017).

\section{California's Low-Carbon Fuel Standard}

The Low-Carbon Fuel Standard (LCFS) was issued in 2007 and took effect in 2010 as a central element of California's Global Warming Solutions Act of 2006 that mandates a reduction in Californian statewide GHG emissions to 1990 levels by 2020.

The LCFS is a market-based cap-and-trade mechanism that mandates a progressive reduction in the carbon intensity of transportation fuels, beginning with $0.25 \%$ in 2011 and reaching a total reduction of $10 \%$ in 2020 compared with 2010 levels. Fuel providers may choose between using cleaner low-carbon transportation fuels (such as liquid biofuels, natural gas, electricity and hydrogen) or buying LCFS credits from other companies that use such fuels. The LCFS includes a life cycle-scale assessment of the carbon content of each fuel used in the LCFS and a calculation of the carbon intensity of each fuel, based on the Greenhouse Gases, Regulated Emissions and Energy Use in Transportation (GREER) model (California Energy Commission 2018). 


\section{California`s Clean Electricity by 2045 Law}

In September 2018, California adopted a law requiring that $100 \%$ of the state's electricity come from carbon-free sources by 2045 (Penn 2018b). An earlier version of the Bill would have required $100 \%$ renewables (wind, solar and geothermal) by 2045 . The final version, SB100, representing a compromise, allows up to $40 \%$ of the state's electricity to come from any zerocarbon technology, potentially including hydropower, nuclear or natural gas paired with carbon capture and storage. Separately, the legally binding target for renewables was increased from $50 \%$ to $60 \%$. In May 2018, California's Energy Commission voted to make solar power panels compulsory in all new homes (Penn 2018a).

\section{Canada's Clean Fuel Standard}

Another example of a low-carbon fuel standard is Canada's forthcoming Clean Fuel Standard (CFS), due to be introduced under the Canadian Environmental Protection Act 1999 as a central element of its climate strategy. The objective of the CFS is to achieve 30 megatonnes of annual reductions in GHG emissions by 2030 , thus contributing to reaching Canada's overall GHG mitigation target of a $30 \%$ reduction below 2005 levels by 2030 . The CFS is expected to cover fuels consumed in the transportation, building and industrial sectors. If this is the case, Canada will become the first jurisdiction in the world to adopt an LCFS which covers all three sectors (Government of Canada 2018).

schedules. Starting in 2018, a gradual increase in industrial fuel prices reaches an international benchmark by 2030 . This scenario is called partial FPR. A potential scenario following a more gradual deregulation pathway, where prices gradually rise to half of the international benchmarks over the course of the projection period, examines what would happen if full price deregulation is not realized before 2030 . This is similar to the energy price reform currently being implemented in the Kingdom. The second FPR scenario would remove price controls on fuel prices entirely with immediate effect from 2018 and allow prices to reach a level determined endogenously in the model by supply and demand. This scenario is called full FPR. 


\section{Modeling Methodology}

The KAPSARC Energy Model for the GCC (KEM-GCC) is a partial equilibrium model of three industrial sectors: fuel supply (oil and gas upstream); power production; and water desalination. Each sector is a cost-minimizing (or profit maximizing) agent. The model is formulated as a mixed-complementary problem (MCP) because the transfer prices for fuels, electricity, and water among sectors are regulated at levels below marginal cost. With this formulation we can model existing fuel pricing policies and perform experiments where prices are formed at the competitive equilibrium. This methodology was previously applied to study the energy-intensive sectors of Saudi Arabia and the role of subsidy reforms (Matar et al. 2017). A mathematical treatment of using MCP for energy systems modeling is available in Murphy et al. (2016).

The fuel supply sector provides fuel inputs to the Saudi power and water sectors. Four fuels are available: crude oil, natural gas, diesel, and heavy fuel oil (HFO). The fuel supply sector can produce fuel from domestic reserves or import from and export to the global market.

The power sector minimizes operating and capital costs to meet exogenous electricity demand. The following technologies are available for operation and deployment in the model: steam turbines, open cycle gas turbines (OCGTs), combined cycle gas turbines (CCGTs), PV, concentrated solar power (CSP), nuclear, and onshore wind. OCGTs can be converted to CCGTs. We discretize exogenous electricity demand into eight hourly loads for two types of days and three seasons for a total of 48 load segments per country. Country specific load curves are presented in Appendix B. This segmentation is sufficient to capture the diurnal variation in electricity demand and also renewable resource availability while balancing model size and solution time. The power sector can purchase and sell electricity from the water sector. The water sector minimizes operating and capital costs to meet exogenous water demand. Demand is specified along the same 48 load segments as the power sector. Both thermal desalination units in the form of multi-stage flash distillation (MSF) and reverse osmosis $(\mathrm{RO})$ are available technologies.

We calibrated the model to closely reproduce fuel consumption and technology utilization reported between 2015 and 2017 by using administered prices (Table 1). 


\section{Modeling Results}

\section{Investments}

Significant capital investment would be required to reduce $\mathrm{CO}_{2}$ emissions from the power and water sectors, as Figure 4 (left) shows. Figure 4 (right) shows total capacity deployments. Under the BAU scenario, the cumulative investment would be around $\$ 60$ billion for $34 \mathrm{GW}$ of capacity. Over half of the deployments are CCGTs (20 GW). The model invests in CCGTs and other fossil-fuel fired generation technologies as a way of continuing consumption of low-priced fuels, rather than investing in costlier technologies like PV (above and beyond the $9.5 \mathrm{GW}$ renewables policy). Nuclear investment reflects the planned $2.8 \mathrm{GW}$ aspiration.

In the Portfolio Standard (PS) scenario, the model is given the option to deploy nuclear or PV to meet capacity requirements ( $30 \mathrm{GW}$ by $2025 ; 48 \mathrm{GW}$ by 2030). The total value of new investment is more than double the amount observed in BAU $(\$ 142$ billion). By 2030 PV accounts for over half and CCGTs for over one-quarter of total additions over the period (70 GW), respectively.
The carbon constraint in the CES scenario altered the economics of each technology even though the underlying subsidies remained intact. As in the BAU and PS scenarios, CCGTs continued to be a competitive technology that was deployed steadily throughout the projection. Without the carbon constraint, investments in this scenario would have been identical to the BAU scenario.

The CES scenario drove the second largest cumulative investment in new capital: \$227 billion over the period to 2030 . Over $77 \%$ of total investment expenditure under the CES scenario was solar PV ( $\$ 175$ billion) for $75 \mathrm{GW}$ of capacity. From 2023 onward, the model deployed over $10 \mathrm{GW}$ at around $\$ 25$ billion annually. To put this amount into perspective, global investment in PV in 2015 was $\$ 98$ billion, as reported by the International Energy Agency (IEA). Of that, total Organization for Economic Cooperation and Development (OECD) investment in 2015 was $\$ 68$ billion - the largest investment coming from Japan at $\$ 27$ billion (IEA 2016). These results show that, while ambitious, there is precedent for $\mathrm{PV}$ deployment of this magnitude. Only the stated $2.8 \mathrm{GW}$ of nuclear was constructed in

Figure 4. Left: Total value of technology investments from 2015 to 2030 by scenario, in $\$$ (billion). Right: Total capacity deployments in GW.
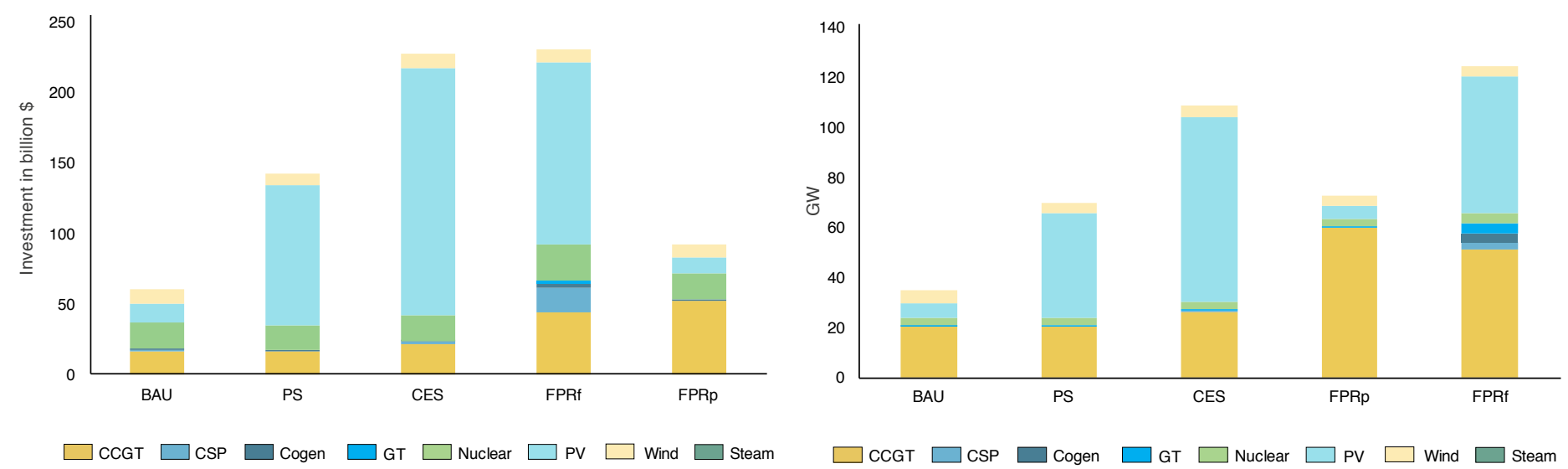

Source: KAPSARC analysis. 
this scenario. Finally, the carbon constraint makes thermal desalination too expensive to operate. In all scenarios, reverse osmosis $(\mathrm{RO})$ desalination capacity is built to supply drinking water.

Investments under the partial FPR (FPRp) scenario are closer to the BAU scenario. CCGTs are the dominant investment $(60 \mathrm{GW}$ or $57 \%$ of total investments) at $\$ 52$ billion. While fuel prices rise over the period to 2030 under the FPRp scenario, the price rise is insufficient to alter the long-run marginal costs and induce a substantial switch to non-fossil technologies.

In the full FPR (FPRf) scenario, nearly $80 \%$ of investments were in non-fossil technologies (66 GW at $\$ 181$ billion total cost for the period to 2030). Unlike the mandates under the PS scenario, the relative costs of fuels substantially changed the short-run marginal costs and spurred investments in lower cost fossil generation (CCGTs) and nonfossil technologies. Additionally, investments in nuclear and PV capacity are made based on the relative costs, not influenced by a mandated carbon constraint. This is reflected in the lower overall volume and value of investment over the period, and in the lower relative investment in solar PV in the FPRf scenario compared to the CES scenario. An additional $0.5 \mathrm{GW}$ of nuclear capacity is deployed in 2029 as base load amid constrained natural gas supply and costlier crude oil. The higher priced fuel inputs also make thermal desalination too expensive to operate. Investments in RO desalination capacity supply drinking water.

\section{Electricity production}

Electricity production by technology provides insight into the way in which emissions pathways develop under these scenarios. Figure 5 presents annual electricity supply through 2030 for each scenario.

The longer-term trends associated with each scenario emerge after 2020. Electricity production

Figure 5. Projected electricity production by technology and scenario (TWh).

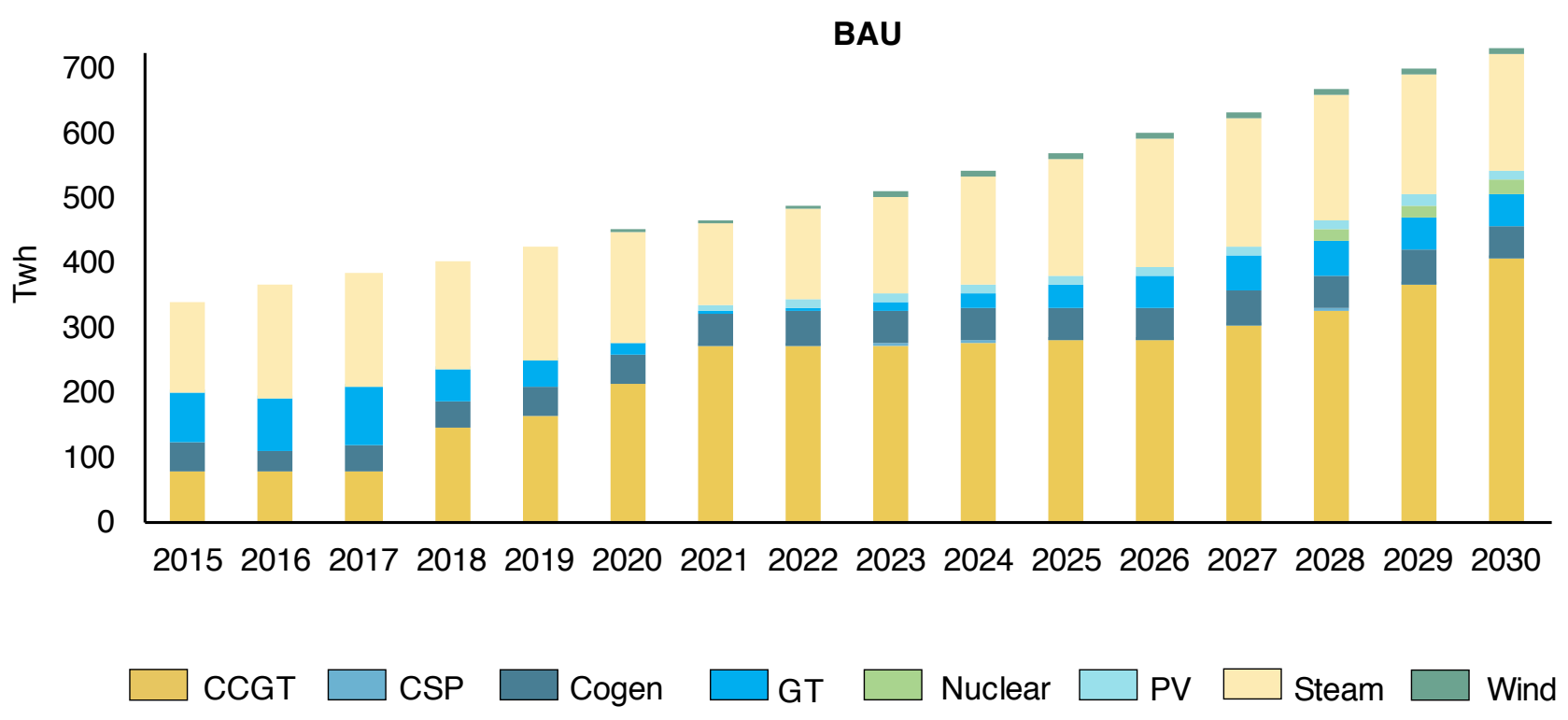




\section{Modeling Results}

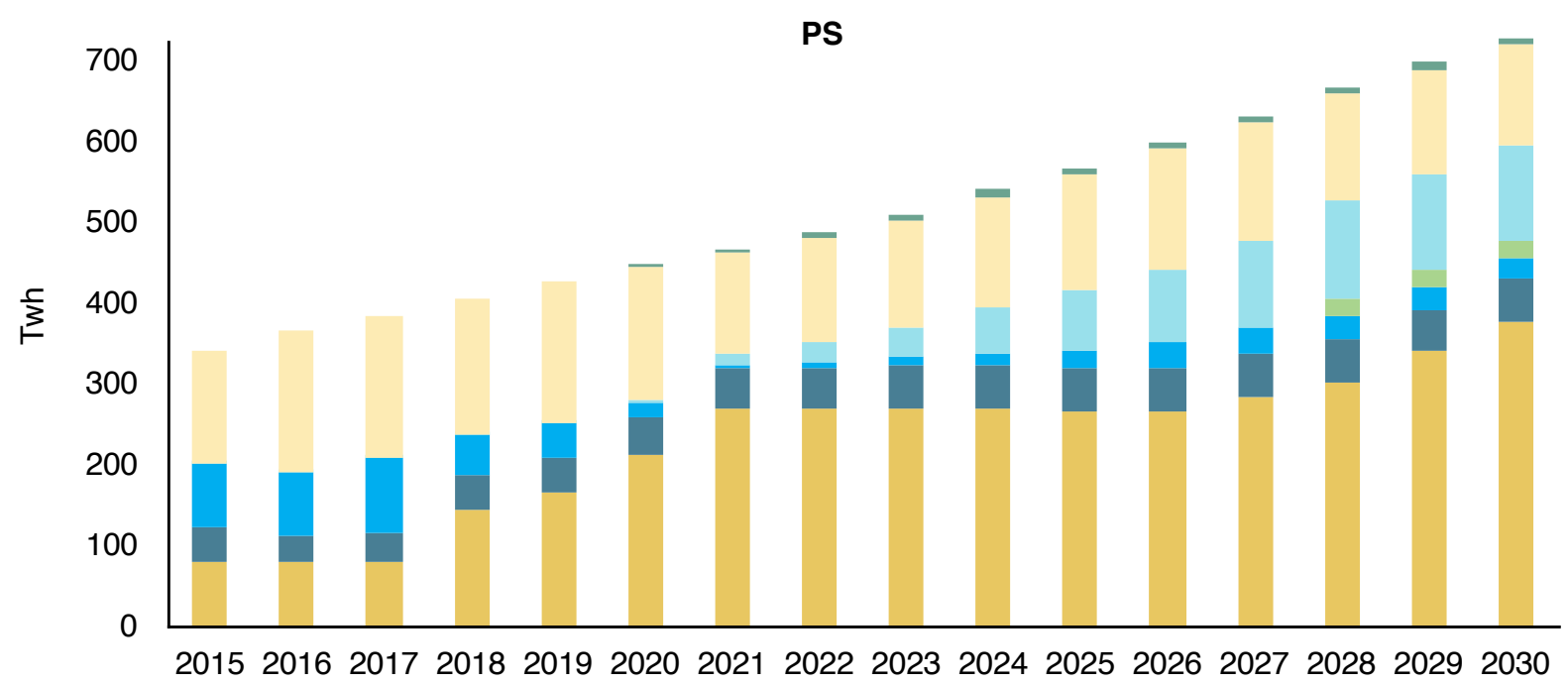

$\square$ CCGT $\square$ CSP $\square$ Cogen $\square$ GT $\square$ Nuclear $\square$ PV $\square$ Steam $\square$ Wind
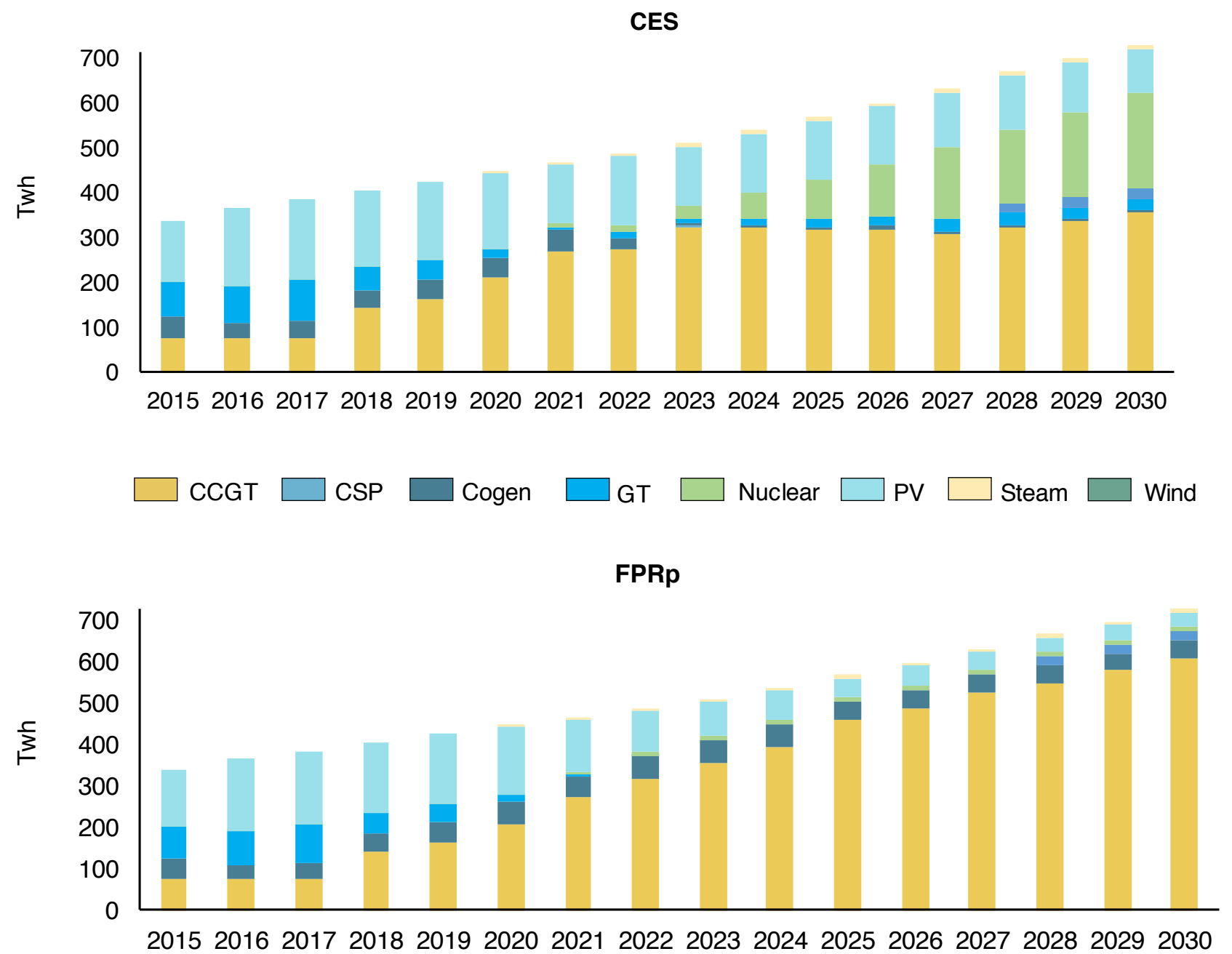

$\square$ CCGT $\square$ CSP $\square$ Cogen $\square$ GT $\square$ Nuclear $\square$ PV $\square$ Steam $\square$ Wind 


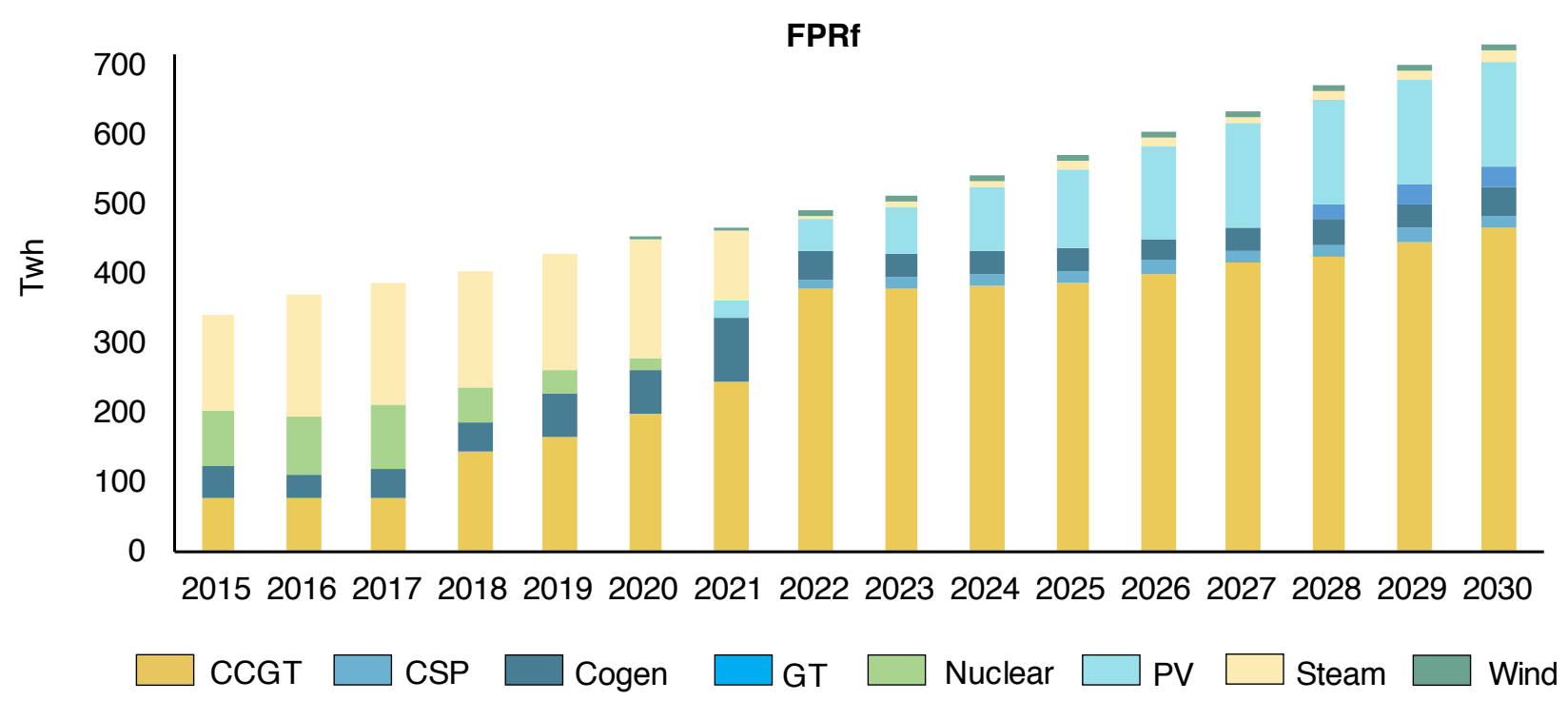

Source: KAPSARC analysis.

in all scenarios increases to just over 400 TWh (up by around $20 \%$ compared to 2015 consumption levels). In the BAU scenario the share of steam and open-cycle turbines falls in 2021 as CCGTs produce more electricity. However, steam generation begins to increase through 2030 because inexpensive fuels are available. The effect of required non-fossil capacity deployment is apparent in the PS scenario. Solar PV generation begins in 2020 and increases to $16 \%$ of generation by 2030 , at the expense of steam and open-cycle generation. As in the BAU scenario, production from CCGTs remains relatively flat for most of the period after 2021.

In the CES scenario, combined non-fossil generation, largely from PV (215 TWh), grows more than the PS scenario, representing around one-third of total electricity generation (224 TWh) in 2030. Cogeneration supplies a smaller proportion of electricity. Overall, electricity supply is slightly greater than in the BAU and PS scenarios because of demand from $R O$ units.
Fuel prices in the FPRp scenario have increased to a level where co-generation and geothermal are less cost-effective. CCGT production fills the gap, accounting for $83 \%$ of all supply (606 TWh) by 2030 . Production by PV is marginal (1.5\%). Electricity production in the FPRf scenario is predominantly a mix of gas-fired CCGTs (64\%) and solar PV (20\%). Electricity production is also higher than scenarios with thermal desalination, reflecting the electricity demand from RO desalination. However, substituting RO units for thermal desalination increases electricity requirements by less than $1 \%$.

\section{Optimal fuel mix}

The optimal fuel mix reflects the short-run marginal cost of electricity production (e.g., fuel costs), accounting for the opportunity cost of oil exports. Figure 6 presents the annual optimal fuel mix for each policy approach through 2030. 
Figure 6. Optimal fuel consumption by scenario, quadrillion British thermal units (QBtu).
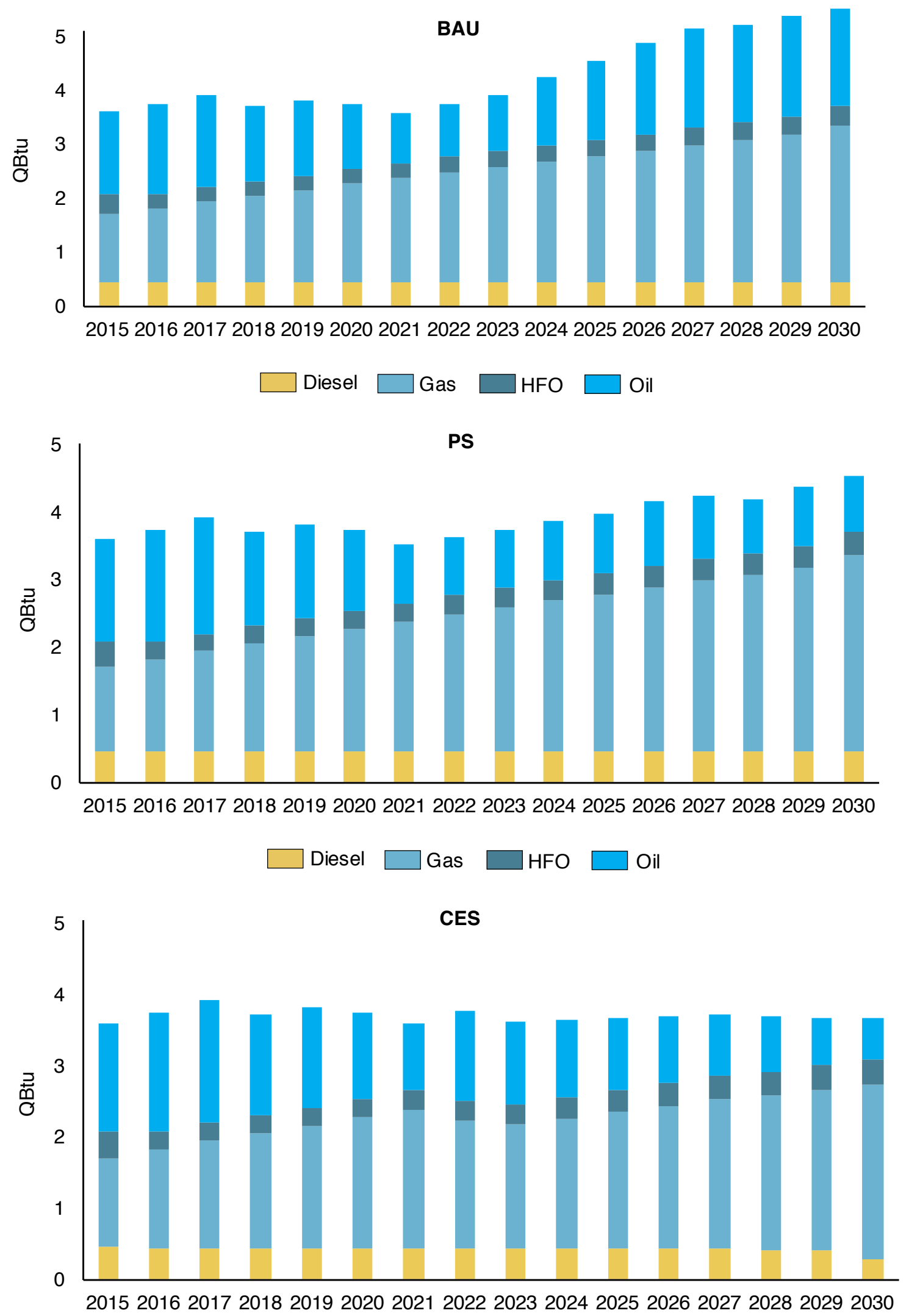

Diesel

Gas

HFO

Oil 

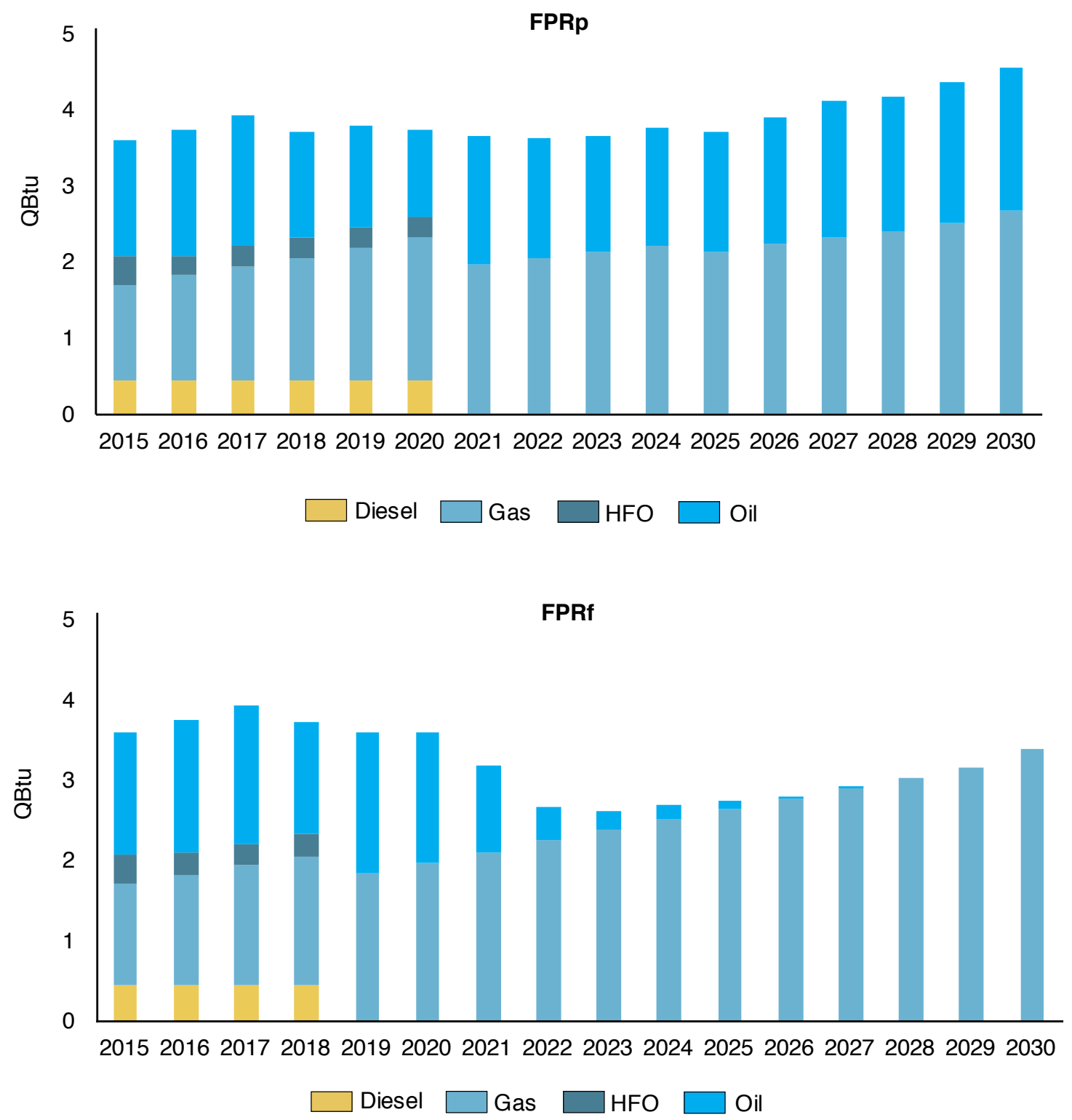

Source: KAPSARC analysis.

In 2017, Saudi Arabia consumed around 3.5 quadrillion British thermal units (QBtu) of energy to produce electricity, using a combination of crude oil, natural gas, diesel and HFO (Figure 6). The relative prices of fuels in BAU have not changed, but the available supply of natural gas has increased, reflecting this paper's assumptions about increasing natural gas production over the period used exclusively to meet domestic demand (Oil \& Gas Journal 2016). As a result, a greater share of crude oil previously consumed to produce domestic electricity is made available for export throughout the simulation period. Total fuel consumption reaches 5.5 QBtu by 2030 .

The addition of PV capacity in the PS scenario reduces the total quantity of fossil fuel consumption by 1.0 QBtu relative to the BAU. Crude oil is offset by PV. 
Fuel consumption in the CES scenario decreases further by 1.0 QBtu relative to the PS to 3.6 QBtu. The addition of PV capacity and efficient CCGTs slows and even reduces the total fuel consumption starting in 2023. Despite these reductions, significant volumes of crude oil, diesel and HFO were still consumed in the CES scenario. While the carbon intensity mandate creates an incentive for $\mathrm{PV}$, the continuing relatively low cost of fossil fuels makes their consumption cost-effective in this scenario. This result illustrates the risks and potential unintended consequences associated with narrow policy approaches that address one aspect of an issue (in this case carbon emissions) without adequately addressing other interrelated factors (in this case the distortion created by the low relative cost of regulated input fuel for power generation).

Fuel prices increase in the FPRp and FPRf scenarios which drives $\mathrm{HFO}$ and diesel out of the fuel mix by 2021 and 2019, respectively. In the FPRp scenario, fuel prices are much lower than the international reference price reached in the FPRf scenario, but the increase is enough to make HFO and diesel too costly to consume. Total fuel consumption in the FPRp scenario is 4.5 QBtu close to the consumption in the PS scenario. Overall fossil fuel consumption is 0.3 QBtu lower than CES in 2030 as a result of the investments in CCGTs, PV, and nuclear technologies as previously discussed. In the FPRf scenario, crude oil is also too costly to consume for power generation. Natural gas is the only fossil fuel consumed (3.4 QBtu).

\section{$\mathrm{CO}_{2}$ emissions}

Unsurprisingly, the carbon emissions abatement outcomes for each scenario are a product of the related sector investment, generation and fuel consumption trends previously discussed. As a result, the policy options examined in this paper deliver varying degrees of economic and environmental benefits. They are also consistent with the Saudi Arabian government's approach to pursuing carbon abatement as an integrated part of a wider economic reform agenda, rather than as an isolated end in itself (Kingdom of Saudi Arabia Vision 2030, 2016).

Power and water sector emissions in BAU grow steadily from 231 million tonnes per annum (mtpa) in 2015 to nearly 400 mtpa in 2030, largely driven by the increasing consumption of crude oil as a feedstock for power generation to meet incremental growth in electricity demand over the period

(Figure 7). Emissions in the PS scenario track with BAU until 2026 when PV deployment is ramped up. The deployment of $48 \mathrm{GW}$ of non-fossil capacity delivers 60 million tonnes of cumulative emissions reductions relative to BAU through 2030.

The FPRp delivers a reduction of 921 million tonnes (mt) of emissions abatement compared to BAU through 2030, reflecting the substantial investment in CCGTs. However, emissions reductions are much lower than under either the CES or FPRf scenarios.

Large emissions reductions are delivered by both the CES and FPRf scenarios through 2030. Both scenarios deliver over 169 mtpa $\mathrm{CO}_{2}$ emissions reductions compared to the BAU scenario in 2030 , representing a decrease of $43 \%$ in the power and water sectors. The CES and FPRf policies result in different emissions pathways. The CES scenario was constructed such that emissions would decline from 2019 until meeting the emissions from FPRf in 2030. The FPRf scenario does not include any ceiling on emissions. The result is that full price reform delivers larger cumulative emissions reductions throughout the simulation period $(1,210$ $\mathrm{mt})$. Emissions reach under $200 \mathrm{mtpa}$ in the years after 2023 but begin to climb thereafter. 
Figure 7. $\mathrm{CO}_{2}$ emissions pathways through 2030, million tonnes per annum (mtpa).

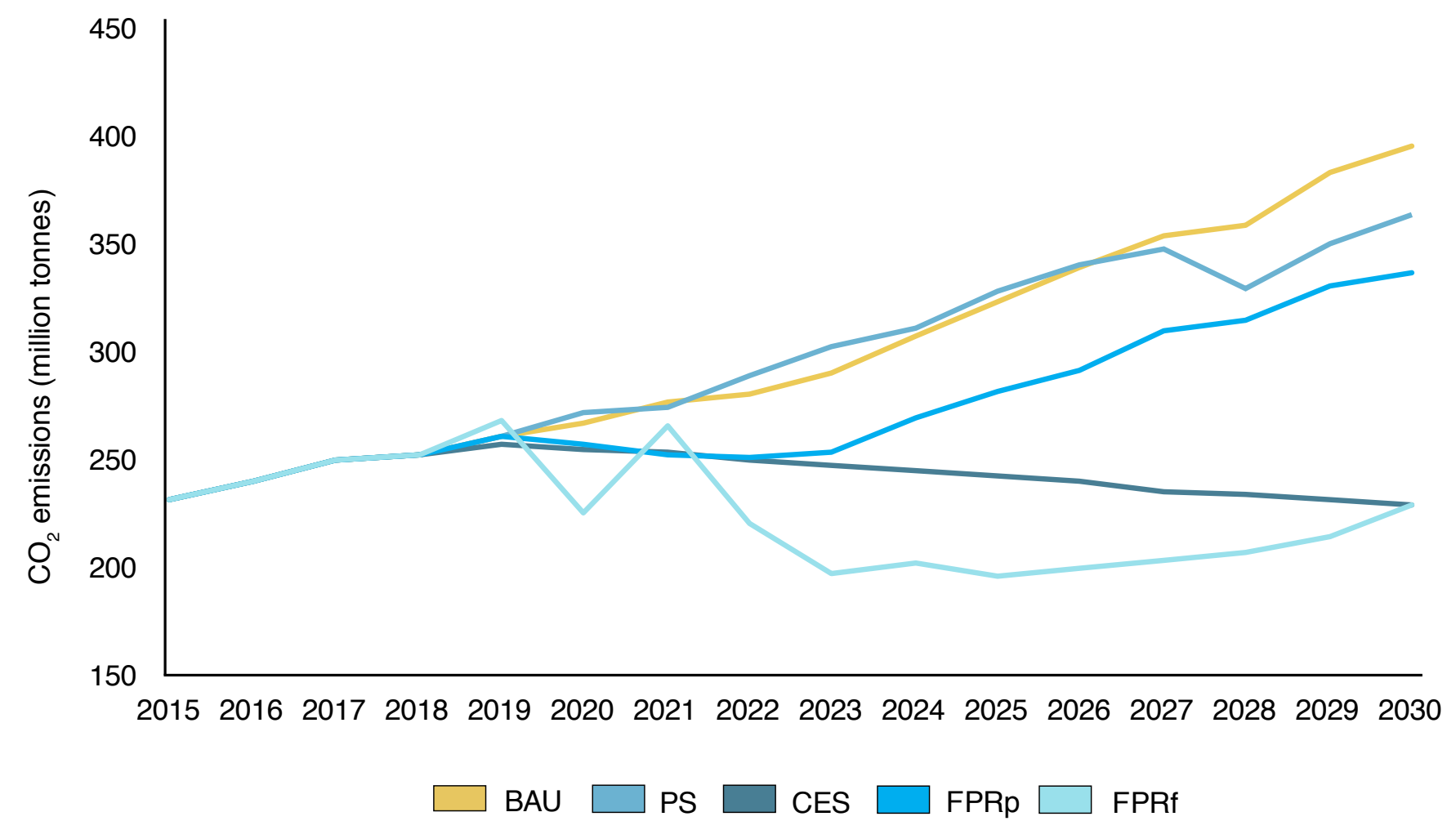

Source: KAPSARC analysis.

Carbon emissions reductions of this magnitude would allow the Kingdom to achieve most of its existing 2030 abatement commitments under the Paris Agreement. Both CES and FPRf scenarios also appear to set the power and water sectors on a more sustainable longer-term decarbonization trajectory. These results reflect the large-scale investment in PV and CCGTs, and the related reduction in fossil fuel feedstock consumed for power generation over the period.

\section{Economic costs and gains}

As shown in the preceding subsections, each policy scenario has impacts on technology investment, fuel consumption, and oil exports. Figure 8 breaks down the level of these three components as a series of waterfall charts to illustrate the net economic impact of each policy relative to BAU.

Net economic gains increase through the CES, PS and FPRf scenarios. The largest contributor to the gains is fuel savings. Fuel savings are calculated as the opportunity cost of fuel consumption relative to BAU, which is intended to capture the effect of moving away from consuming fuels priced below market prices. This result also showcases the degree to which fuels are subsidized. Fully reforming fuel prices, as in FPRf, would result in the largest economic gain: $\$ 911$ billion cumulatively between 2015 and 2030.

Only the FPRp scenario experiences a negative net impact. Partially increasing fuel prices increases 
Figure 8. Economic costs and gains by climate policy scenario relative to BAU (billion \$).
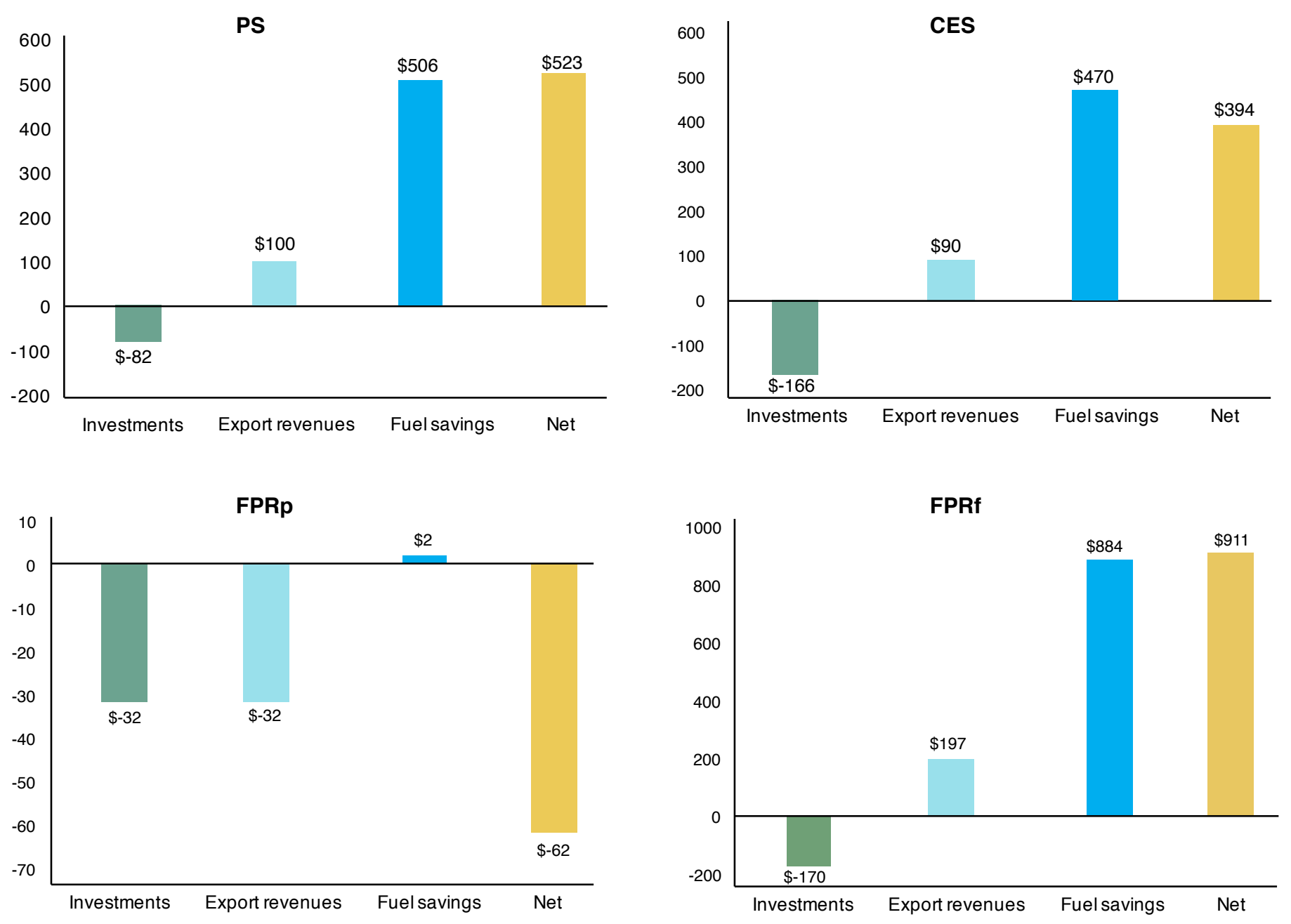

Source: KAPSARC analysis.

costs without imparting economic benefit from oil exports or fuel savings. The fuel prices in this scenario are high enough to induce investment in CCGTs but not high enough to build substantial PV or other non-fossil fuel technologies. As shown in Figure 6, the power system is nearly $50 \%$ fueled by crude oil. This consumption reduces oil for exports and, subsequently, the savings from fuel consumption. This policy scenario not only achieves small $\mathrm{CO}_{2}$ emissions reductions but results in a net negative to the Saudi Arabian power and water sectors. This result illustrates the potential unintended consequences and hidden costs of a policy as price reforms are not substantial enough to drive deployment of low-carbon technologies. 


\section{Conclusion}

he 2015 Paris Agreement fundamentally altered the nature of global cooperation to address climate change by introducing a decentralized approach that enables countries to more effectively respond to the challenge, based on their specific socio-economic circumstances and resource endowments. Saudi Arabia developed its first NDC to reflect the challenges and opportunities it faces as an energy-intensive economy and leading global oil exporter in an increasingly carbonconstrained world. The Kingdom's NDC aims to support the economic diversification of its economy while delivering climate co-benefits.

This paper evaluated several policy approaches to mitigate $\mathrm{CO}_{2}$ emissions from the Saudi power and water sectors, which, combined, contribute over $40 \%$ of the country's GHG emissions. These approaches build on existing efforts to expand nonfossil electricity production and energy sector reform as part of Vision 2030.

Rationalizing costs of fuel inputs is critical to driving large $\mathrm{CO}_{2}$ emissions reductions and providing a net economic benefit to the Saudi Arabian economy. Fully deregulating fuel prices delivers the largest $\mathrm{CO}_{2}$ emissions reductions of the scenarios considered in this study (1.2 billion tonnes cumulative through 2030) while also providing a $\$ 911$ billion net economic benefit. In this policy scenario, the power system supplies electricity demand mainly through natural gas-fired CCGTs (64\%) and solar PV (20\%).

A CES designed to achieve similar reductions could also deliver a positive net economic benefit of \$394 billion. While deep $\mathrm{CO}_{2}$ cuts can be achieved, oil is still consumed for domestic power production which reduces revenues from oil exports and fuel costs. This policy scenario has the benefit of placing a ceiling on emissions while allowing for flexibility to choose the most cost-effective technologies, rather than mandating technologies (e.g., requiring generation from nuclear or PV). The specific design of a CES and its pathway will influence the schedule of investments. Therefore, the estimated costs and benefits presented in this paper are more illustrative of the concept.

A PS is not necessarily an effective policy to reduce $\mathrm{CO}_{2}$ emissions. In this analysis, only modest $\mathrm{CO}_{2}$ emissions cuts were observed, despite the deployment of nearly $50 \mathrm{GW}$ of solar PV. Such a policy should be designed with short-run marginal costs (fuel substitution) and long-run marginal costs (technology investment) to achieve deeper $\mathrm{CO}_{2}$ emissions reductions.

Among other issues, these insights highlight the potential risks associated with implementing climateoriented policies in the power sector in the presence of regulated fuel prices. A more effective policy approach in the Saudi Arabian context would seek to fully deregulate fuel prices before proceeding with subsequent policy interventions to reduce carbon emissions in the power and water sectors. This would help to avoid unintended consequences and compound existing distortions in the economy. The results show that several potential opportunities exist for Saudi Arabia to capitalize on its energy diversification strategy to help deliver substantial $\mathrm{CO}_{2}$ emissions reductions consistent with achieving its carbon abatement goals. 


\section{References}

Bodansky, Daniel. 2011. "A Tale of Two Architectures: The Once and Future U.N. Climate Change Regime." SSRN Electronic Journal, March. https://doi.org/10.2139/ ssrn.1773865

BP. 2017. "BP Statistical Review of World Energy 2017." https://www.bp.com/content/dam/bp/en/corporate/pdf/ energy-economics/statistical-review-2017/bp-statisticalreview-of-world-energy-2017-full-report.pdf

California Energy Commission. 2018. "Low Carbon Fuel Standard." 2018. http://www.energy.ca.gov/low carbon fuel standard/index.html

Department of Energy and Climate Change, UK. 2013. "Energy Act: Emissions Performance Standard." https://assets.publishing.service.gov.uk/government/ uploads/system/uploads/attachment data/file/266882/ EPS Policy Brief RA.pdf

- - - 2014. "Implementing the Emissions

Performance Standard."September 2014.

https://www.gov.uk/government/consultations/

implementing-the-emissions-performance-standard

Erbach, Gregor. 2015. "Doha Amendment to the Kyoto Protocol." http://www.europarl.europa.eu/EPRS/EPRSAaG-559475-Doha-Agreement-Kyoto-Protocol-FINAL.pdf

European Commission. 2016. "The Industrial Emissions Directive - Environment - European Commission.” 2016. http://ec.europa.eu/environment/industry/stationary/ied/ legislation.htm

- - - 2017. "Comitology Register." 2017. http:// ec.europa.eu/transparency/regcomitology/index. cfm?do=search.dossierdetail\&Dos ID=14177\&dos year $=2017 \& d c \quad$ id $=5446$

Ferroukh, Rabia, Arslan Khalid, Diala Hawila, Divyam Nagpal, Laura El-Katiri, Vasilis Fthenakis, and Aref Al-Fara. 2016. Renewable Energy Market Analysis: The GCC Region. http://www.irena.org/-/media/Files/IRENA/ Agency/Publication/2016/IRENA_Market_GCC_2016.pdf

Government of Canada. 2018. "Clean Fuel Standard
- Canada.Ca." 2018. https://www.canada.ca/en/ environment-climate-change/services/managingpollution/energy-production/fuel-regulations/clean-fuelstandard.html

Government of Dubai. 2016. "The Dubai Municipality Report 2016." Dubai. https://www. dm.gov.ae/wps/wcm/connect/ef0b412e-e8fe-480b9c37-fa103cf491aa/compressed DM+Report++Low-res+Single+Pages+\%28Secured\%29. pdf?MOD=AJPERES

International Energy Agency. 2016. World Energy Investment 2016.

- - . 2018. "Oil Market Report." https://www.iea.org/ media/omrreports/fullissues/2018-01-19.pdf

Kingdom of Saudi Arabia GaStat. 2018. "General Authority for Statistics." 2018. https://www.stats.gov.sa/en

Kingdom of Saudi Arabia Vision 2030. 2016. "National Transformation Program 2020." http://vision2030.gov.sa/ en/ntp

Matar, Walid, Frederic Murphy, Axel Pierru, Bertrand Rioux, and David Wogan. 2017. "Efficient Industrial Energy Use: The First Step in Transitioning Saudi Arabia's Energy Mix." Energy Policy 105 (June 2017): 80-92. https://doi.org/10.1016/j.enpol.2017.02.029

Minocha, Aashna. 2018. "Saudi Petrol Prices Are Still Among The World's Cheapest Despite the Price Hike." Forbes Middle East. 2018. https://www.forbesmiddleeast. com/en/saudi-petrol-prices-are-still-among-the-worldscheapest-despite-the-price-hike/

Mohammed, Irfan. 2018. "Threefold Increase in Electricity Bills from Today - Saudi Gazette." 2018. http:// saudigazette.com.sa/article/525167/SAUDI-ARABIA/ Threefold-increase-in-electricity-bills-from-today

Murphy, Frederic, Axel Pierru, and Yves Smeers. 2016. "A Tutorial on Building Policy Models as MixedComplementarity Problems." Interfaces 46 (6): 1-17. https://doi.org/https://doi.org/10.1287/inte.2016.0842 
Nereim, Vivian, and Stephen Cunningham. 2018. "Saudis, SoftBank Plan World's Largest Solar Project" Bloomberg. 2018. https://www.bloomberg.com/news/ articles/2018-03-28/saudi-arabia-softbank-ink-deal-on200-billion-solar-project

Oil \& Gas Journal. 2016. "Aramco to Nearly Double Natural Gas Production in Decade." March 9. http:// www.ogj.com/articles/2016/03/aramco-to-nearly-doublenatural-gas-production-in-decade.html

OPEC (Organization of the Petroleum Exporting Countries). 2018. "OPEC : Saudi Arabia." 2018. http:// www.opec.org/opec web/en/about us/169.htm

Penn, Ivan. 2018a. "California Will Require Solar Power for New Homes." The New York Times, May 19. https://www.nytimes.com/2018/05/09/business/energyenvironment/california-solar-power.html

- - - 2018b. "California Lawmakers Set Goal for Carbon-Free Energy by 2045." The New York Times, August 28. https://www.nytimes.com/2018/08/28/ business/energy-environment/california-clean-energy. html

The White House. 2015. "U.S.-China Joint Presidential Statement on Climate Change." Whitehouse.Gov. September 25. https://obamawhitehouse.archives.gov/ the-press-office/2015/09/25us-china-joint-presidentialstatement-climate-change

U.S. Energy Information Administration. 2012. "Most States Have Renewable Portfolio Standards." https:// www.eia.gov/todayinenergy/detail.php?id=4850
United Nations Framework Convention on Climate Change. 1992. "United Nations Framework Convention on Climate Change." http://unfccc.int/files/essential background/background publications htmlpdf/ application/pdf/conveng.pdf

- - - 1998. "Kyoto Protocolto the United Nations Framework Convention on Climate Change." https:// unfccc.int/resource/docs/convkp/kpeng.pdf

- - - 2011. "Essential Background - Durban

Outcomes." 2011. https://unfccc.int/process/

conferences/the-big-picture/milestones/

outcomes-of-the-durban-conference

- - - 2015. "The Intended Nationally Determined Contribution of the Kingdom of Saudi Arabia under the UNFCCC." http://www4.unfccc.int/Submissions/INDC/ Published Documents/Saudi Arabia/1/KSA-INDCs English.pdf

- - - 2018a. "Paris Agreement - Status of Ratification." https://unfccc.int/process/the-paris-agreement/ status-of-ratification

- - - 2018b. "Timeline UNFCCC 20 Years of Effort and Achiement." http://unfccc.int/timeline/

Wogan, David, Shreekar Pradham, and Shahad Albard. 2017. GCC Energy System Overview - 2017. KS-2017-MP04. Riyadh. KAPSARC. https://www.kapsarc. org/wp-content/uploads/2017/11/KS-2017-MP04-GCCEnergy-Overview-2017.pdf

WRI (World Resources Institute). 2015. "CAIT Climate Data Explorer." http://www.wri.org/resources/ data-visualizations/cait-climate-data-explorer 


\section{Notes}

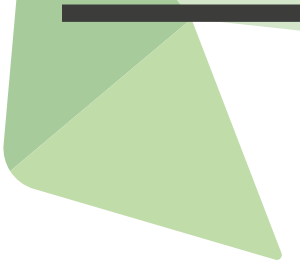


Notes

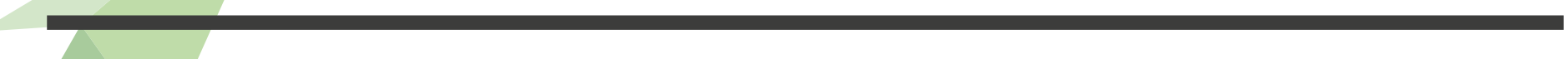




\section{Appendix A: Vision 2030 and the Paris Agreement}

\section{Vision 2030 and the National Transformation Program}

Vision 2030 aims to reduce Saudi Arabia's dependence on oil, diversify its economy and create employment opportunities. Its economic and energy sector objectives include:

Increasing the private sector's contribution from $40 \%$ to $65 \%$ of gross domestic product (GDP).

Increasing small and medium-sized enterprise contribution to GDP from $20 \%$ to $35 \%$.

Increasing the localization of oil and gas sectors from $40 \%$ to $75 \%$.

Raising the share of non-oil exports in non-oil GDP from $16 \%$ to $50 \%$.

Increasing non-oil government revenue from 163 billion Saudi riyals (SAR) to 1 trillion SAR.

The National Transformation Program 2020 (NTP), published in May 2016, is designed to help implement Vision 2030. It seeks private sector investment in non-oil sectors such as tourism, petrochemicals, banking and financial services, construction, manufactured products and mining. Privatization, in full or in part, is planned for sectors such as health, education, aviation and energy.

The NTP sets strategic objectives for ministries to be reached by 2020 and includes 346 targets. Each ministry's strategic objective is linked to the relevant Vision 2030 objectives. Key performance indicators will measure progress toward the implementation of the program.
The Energy Ministry's strategic objectives under the NTP include:

Increasing non-oil commodities exports (objective 1).

Increasing fuel utilization efficiency in the electricity sector (Objective 5).

Enhancing primary sources and security of electricity supplies (Objective 8).

Privatizing the electricity sector (Objective 10).

Reducing fuel consumption emissions (Objective 12).

\section{The Paris Agreement}

The Paris Agreement is the outcome of the Durban Platform for Enhanced Action that in 2011 launched "a process to develop a protocol, another legal instrument or an agreed outcome with legal force under the Convention applicable to all Parties and was to complete its work as early as possible but no later than 2015" (UNFCC 2011).

The Agreement was adopted on Dec. 12, 2015, by 195 signatory Parties at the 21st session of the Conference of the Parties to the UNFCCC (the Convention) in Paris (COP 21). It entered into force on Nov. 4, 2016, 30 days after the date on which at least 55 Parties to the Convention (out of 197 Parties), accounting for an estimated $55 \%$ of the total global greenhouse gas (GHG) emissions, deposited their instruments of ratification, acceptance, approval or accession with the Depositary. As of February 2019, it has been ratified by 184 Parties (UNFCCC 2018).

The objective of the Agreement is stated in Article 2: 


\section{1}

This Agreement, in enhancing the implementation of the Convention, including its objective, aims to strengthen the global response to the threat of climate change, in the context of sustainable development and efforts to eradicate poverty, including by:

a) Holding the increase in the global average temperature to well below 2 degrees Celsius above pre-industrial levels and pursuing efforts to limit the temperature increase to 1.5 degrees above pre-industrial levels, recognizing that this would significantly reduce the risks and impacts of climate change.

b) Increasing the ability to adapt to the adverse impacts of climate change and foster climate resilience and low GHG emissions development, in a manner that does not threaten food production.

c) Making finance flows consistent with a pathway toward low carbon GHG emissions and climate-resilient development.

\section{2}

This Agreement will be implemented to reflect equity and the principle of common but differentiated responsibilities and respective capabilities, in the light of different national circumstances.

To achieve the long-term temperature goal as set out in Article 2, Article 3 states that "Parties aim to reach global peaking of GHG emissions as soon as possible, recognizing that peaking will take longer for developing country Parties, and to undertake rapid reductions thereafter in accordance with best available science so as to achieve a balance between anthropogenic emissions by sources and removals by sinks in the second half of this century on the basis of equity, and in the context of sustainable development and efforts to eradicate poverty."

Alongside mitigation, adaptation features as a key objective of the Agreement. It is given greater prominence alongside mitigation in the Paris Agreement compared with the Kyoto Protocol, in recognition of the fact that "adaptation is a global challenge faced by all with local subnational, national and regional and international dimensions, and that it is a key component of and makes a contribution to the long-term global response to climate change to protect people, livelihoods and ecosystems" (Article 7.2).

The Paris Agreement includes the following clauses in support of mitigation and adaptation:

The conservation and enhancement of sinks and reservoirs of GHGs, including forests (Article 5).

Internationally transferred mitigation outcomes to achieve the NDCs (Article 6).

Adaptation responses to strengthen resilience and reduce vulnerability to climate change (Article 7).

Loss and damage (Article 8).

Scaled-up climate finance (Article 9).

Technology development and transfer (Article 10).

Capacity Building (Article 11). 


\section{Appendix B: Nationally Determined Contributions}

\section{Nationally Determined Contributions: the rules (Article 4)}

Each party shall prepare, communicate and maintain successive nationally determined contributions that it intends to achieve. Parties shall pursue domestic mitigation measures, with the aim of achieving the objectives of such contributions (Article 4.2).

Each Party's successive nationally determined contribution will represent a progression beyond the Party's then current nationally determined contribution and reflect its highest possible ambition (Article 4.3).

In communicating their nationally determined contributions, all Parties shall provide the information necessary for clarity, transparency and understanding (Article 4.8).

Each Party shall communicate a nationally determined contribution every five years (Article 4.9).

Each Party may at any time adjust its existing nationally determined contribution to enhance its level of ambition (Article 4.11).

Parties shall account for their nationally determined contributions, by accounting for anthropogenic emissions and removals corresponding to their nationally determined contributions (Article 4.13).

All Parties should strive to formulate and communicate long-term low greenhouse gas emission development strategies (Article 4.19).
Parties should take into consideration the concerns of Parties with economies most affected by the impacts of response measures, particularly developing country Parties (Article 4.15).

\section{The transparency and implementation framework (Articles 13, 14, 15)}

An enhanced transparency framework with "in-built flexibility which takes into account Parties' different capacities" and which shall be "implemented in a facilitative, non-intrusive, non-punitive manner, respectful of national sovereignty, and avoid placing undue burden on Parties" (Article 13).

A compliance mechanism which is "to consist of a committee that shall be expert-based and facilitative in nature and function in a manner that is transparent, non-adversarial and non-punitive" (Article 15).

A global stock-take which will assess collective progress in implementing the Agreement, with a first global stock-take scheduled for 2023 (Article 14.1 and 14.2).

\section{Principles referred to in Saudi Arabia's first Nationally Determined Contribution}

\section{Article 3 (Principles), paragraph 2 of the Convention}

The specific needs and special circumstances of developing country Parties, especially those that are particularly vulnerable to the adverse effects 
of climate change, and of those Parties, especially developing country Parties that would have to bear a disproportionate or abnormal burden under the Convention, should be given full consideration.

\section{Article 4 (Commitments), paragraph 8 (h) of the Convention}

In the implementation of the commitments in this Article, the Parties shall give full consideration to what actions are necessary under the Convention, including actions related to funding, insurance and the transfer of technology, to meet the specific needs and concerns of developing country Parties arising from the adverse effects of climate change and/or the impact of the implementation of response measures, especially on:

(h) Countries whose economies are highly dependent on income generated from the production, processing and export, and/or on consumption of fossil fuels and associated energy-intensive products.

\section{Article 4 (Commitments), paragraph 10 of the Convention}

The developed country Parties and other developed Parties included in Annex II shall also assist the developing country Parties that are particularly vulnerable to the adverse effects of climate change in meeting costs of adaptation to those adverse effects.

\section{Economic Diversification Initiative, adopted as UNFCCC decision 24/CP.18}

Recognizing that climate change calls for the widest possible cooperation by all countries, and that measures taken by Parties on their lowemission development path and Parties' efforts to diversify their economies will reflect their national circumstances. 


\section{Appendix C. The Path to the Paris Agreement}

\section{The UNFCCC or "the Convention"}

The adoption of the UNFCCC (the Convention) by 197 signatory Parties at the Rio Summit in 1992 created the overarching framework of the global climate governance regime. Article 2 of the Convention states that its ultimate objective is to stabilize greenhouse gas (GHG) concentrations "at a level that would prevent dangerous anthropogenic interference with the climate system." Article 3 states that "the Parties should protect the climate system for the benefit of present and future generations of mankind, on the basis of equity and in accordance with their common but differentiated responsibilities and respective capabilities. Accordingly, the developed country Parties should take the lead in combating climate change and the adverse effects thereof." Article 3 of the Convention established a fundamental distinction between Annex I countries (member countries of the OECD as well as economies in transition) which committed to reducing their GHG emissions and non-Annex I countries (the developing countries) which were free of such commitments (UNFCCC 1992).

\section{The Kyoto Protocol}

The UNFCCC is the parent treaty of the 1997 Kyoto Protocol, which entered into force in 2005 (UNFCCC 1998). The Kyoto Protocol reinforced the divide between Annex I and non-Annex I countries by adopting a rigid, top-down approach with legally binding, quantified emissions reduction targets, imposed only on Annex I countries over the course of both its commitment periods (2008-2012 and 2012-2020). This approach led to several of its
Annex-I signatory Parties either not ratifying the Protocol (the United States), leaving the Protocol (Canada), or declining to participate in a second commitment period (Russia, Japan, New Zealand).

\section{The Bali Action Plan and the 2009 Copenhagen Conference}

The entry into force of the Kyoto Protocol in 2005 led to the opening of a double-track process of negotiations: one between the Parties to the Kyoto Protocol to negotiate a second commitment period, the other between all 197 UNFCCC Parties to promote long-term cooperation under the 2007 Bali Action Plan.

This double-track process met with failure at the Copenhagen Climate Change Conference in 2009 (COP 15). The conference did, however, produce the Copenhagen Accord which was ultimately endorsed by over 140 countries including China, India, Brazil, as well as a significant number of developed and developing countries. The Copenhagen Accord began the process of eroding the top-down, legally binding, sharp differentiation architecture of the Kyoto Protocol (UNFCCC 2009). Annex I Parties were now committed to implementing quantified economy-wide reduction emissions targets by 2020 (Article 4), with many Non-Annex I Parties also agreeing to implement nationally appropriate mitigation actions. Least developed countries and small island developing states could undertake actions voluntarily and with support (Article 5). This paradigm shift was formally integrated into the UNFCCC process in 2010 with the adoption of the Cancun/Copenhagen agreements at COP 16 (UNFCCC 2018b). 


\section{The Durban Platform for Enhanced Action and the Mandate for Paris}

The Durban Platform for Enhanced Action (COP 17 2011) launched the formal process leading up to Paris. The Durban outcome led to a second commitment period for the Kyoto Protocol up until 2020 (adopted in 2012 as the Doha Amendment) and launched "a process to develop a protocol, another legal instrument or an agreed outcome with legal force under the Convention applicable to all Parties" (Article 2). The Durban Platform was to "complete its work as early as possible but no later than 2015" (Article 4).

The 2011 Durban mandate led to the ADP meeting move than 15 times over the next four years, creating a series of significant milestones on the way to Paris, particularly at Warsaw (COP 19) and Lima (COP 20). The Warsaw Conference established a new Mechanism for Loss and Damage as well as the Warsaw Framework for REDD+ to reduce emissions from deforestation and degradation. The Lima Call for Action (COP 20) called on all UNFCCC Parties to submit their
Intended Nationally Determined Contributions (INDCs) ahead of COP 21. By the opening of the Paris Conference, most Parties had already submitted their INDCs, which meant that much of the bottom-up part of the Agreement was already in place by December 2015 (Bodansky 2011).

\section{U.S.-China Joint Announcement on Climate Change}

The joint announcement by the United States (U.S.) and China on climate change made in November 2014, in which the U.S. and China were the first major countries to announce their post-2020 targets, acted as a powerful catalyst for action ahead of COP 21. The U.S. and China hoped that "by announcing these targets now, they can inject momentum into the global climate negotiations and inspire other countries to join in coming forward with ambitious actions as soon as possible." The U.S.-China declaration was the game changer that gave the negotiating Parties and the international community at large confidence that the Paris Conference would have a successful outcome (The White House 2014). 


\section{Appendix D: Cost Assumptions}

Table 1B. Technology costs in \$/GW.

\begin{tabular}{l|l|l|l|l|l|l|l} 
Year & ST and GT & ST with scrubber & \multicolumn{1}{l}{ CCGT } & Nuclear & PV & CSP & Wind \\
\hline 2016 & 1026 & 1231 & 1778 & 6158 & 1778 & 7872 & 1529 \\
\hline 2017 & 1026 & 1231 & 1212 & 6154 & 1212 & 7565 & 1508 \\
\hline 2018 & 1026 & 1231 & 1065 & 6151 & 1065 & 7258 & 1488 \\
\hline 2019 & 1026 & 1231 & 1024 & 6147 & 1024 & 6950 & 1469 \\
\hline 2020 & 1026 & 1231 & 964 & 6143 & 964 & 6643 & 1450 \\
\hline 2021 & 1026 & 1231 & 914 & 6140 & 914 & 6559 & 1433 \\
\hline 2022 & 1026 & 1231 & 904 & 6136 & 904 & 6475 & 1416 \\
\hline 2023 & 1026 & 1231 & 893 & 6111 & 893 & 6392 & 1399 \\
\hline 2024 & 1026 & 1231 & 883 & 6075 & 883 & 6308 & 1383 \\
\hline 2026 & 1026 & 1231 & 873 & 6044 & 873 & 6224 & 1368 \\
\hline 2027 & 1026 & 1231 & 862 & 6004 & 862 & 6141 & 1354 \\
\hline 2028 & 1026 & 1231 & 852 & 5976 & 852 & 6057 & 1340 \\
\hline 2030 & 1026 & 1231 & 842 & 5951 & 842 & 5973 & 1327 \\
\hline
\end{tabular}

Source: NREL, IEA.

Table 2B. Fixed O\&M in $\$ / G W h$.

\begin{tabular}{|c|c|c|c|c|c|}
\hline Year & ST, GT, CCGT & ST with scrubber & PV & Wind & Nuclear \\
\hline 2016 & 3420 & 4430 & 14 & 51 & 99 \\
\hline 2017 & 3420 & 4430 & 10 & 51 & 99 \\
\hline 2018 & 3420 & 4430 & 9 & 51 & 99 \\
\hline 2019 & 3420 & 4430 & 9 & 50 & 99 \\
\hline 2020 & 3420 & 4430 & 8 & 50 & 99 \\
\hline 2021 & 3420 & 4430 & 8 & 49 & 99 \\
\hline 2022 & 3420 & 4430 & 7 & 49 & 99 \\
\hline 2023 & 3420 & 4430 & 7 & 49 & 99 \\
\hline 2024 & 3420 & 4430 & 7 & 48 & 99 \\
\hline 2025 & 3420 & 4430 & 7 & 48 & 99 \\
\hline 2026 & 3420 & 4430 & 7 & 48 & 99 \\
\hline 2027 & 3420 & 4430 & 7 & 47 & 99 \\
\hline 2028 & 3420 & 4430 & 7 & 47 & 99 \\
\hline 2029 & 3420 & 4430 & 7 & 47 & 99 \\
\hline 2030 & 3420 & 4430 & 7 & 46 & 99 \\
\hline
\end{tabular}

Source: NREL, IEA. 
Table 3B. Fixed O\&M costs in \$/GW.

\begin{tabular}{l|l|l|l|l|l|l} 
Year & ST, GT & CCGT & PV & \multicolumn{2}{l}{ Wind } & \multicolumn{2}{l}{ CSP } & Nuclear \\
\hline 2016 & 17.2 & 10.7 & 24 & 210 & 4.1 & 2.3 \\
\hline 2017 & 17.2 & 10.7 & 24 & 210 & 4.1 & 2.3 \\
\hline 2018 & 17.2 & 10.7 & 24 & 210 & 4.1 & 2.3 \\
\hline 2019 & 17.2 & 10.7 & 24 & 210 & 4.1 & 2.3 \\
\hline 2020 & 17.2 & 10.7 & 24 & 210 & 3.5 & 2.3 \\
\hline 2021 & 17.2 & 10.7 & 24 & 210 & 3.5 & 2.3 \\
\hline 2022 & 17.2 & 10.7 & 24 & 210 & 3.5 & 2.3 \\
\hline 2023 & 17.2 & 10.7 & 24 & 210 & 3.5 & 2.3 \\
\hline 2024 & 17.2 & 10.7 & 24 & 210 & 3.5 & 2.3 \\
\hline 2025 & 17.2 & 10.7 & 24 & 210 & 3.5 & 2.3 \\
\hline 2026 & 17.2 & 10.7 & 24 & 210 & 3.5 & 2.3 \\
\hline 2027 & 17.2 & 10.7 & 24 & 210 & 3.5 & 2.3 \\
\hline 2028 & 17.2 & 10.7 & 24 & 210 & 3.5 & 2.3 \\
\hline 2029 & 17.2 & 10.7 & 24 & 210 & 3.5 & 2.3 \\
\hline
\end{tabular}

Source: NREL, IEA. 


\section{Appendix E: Annual Technology Investments}

Figure 9. Annual investments by technology in billion $\$$ (2015).

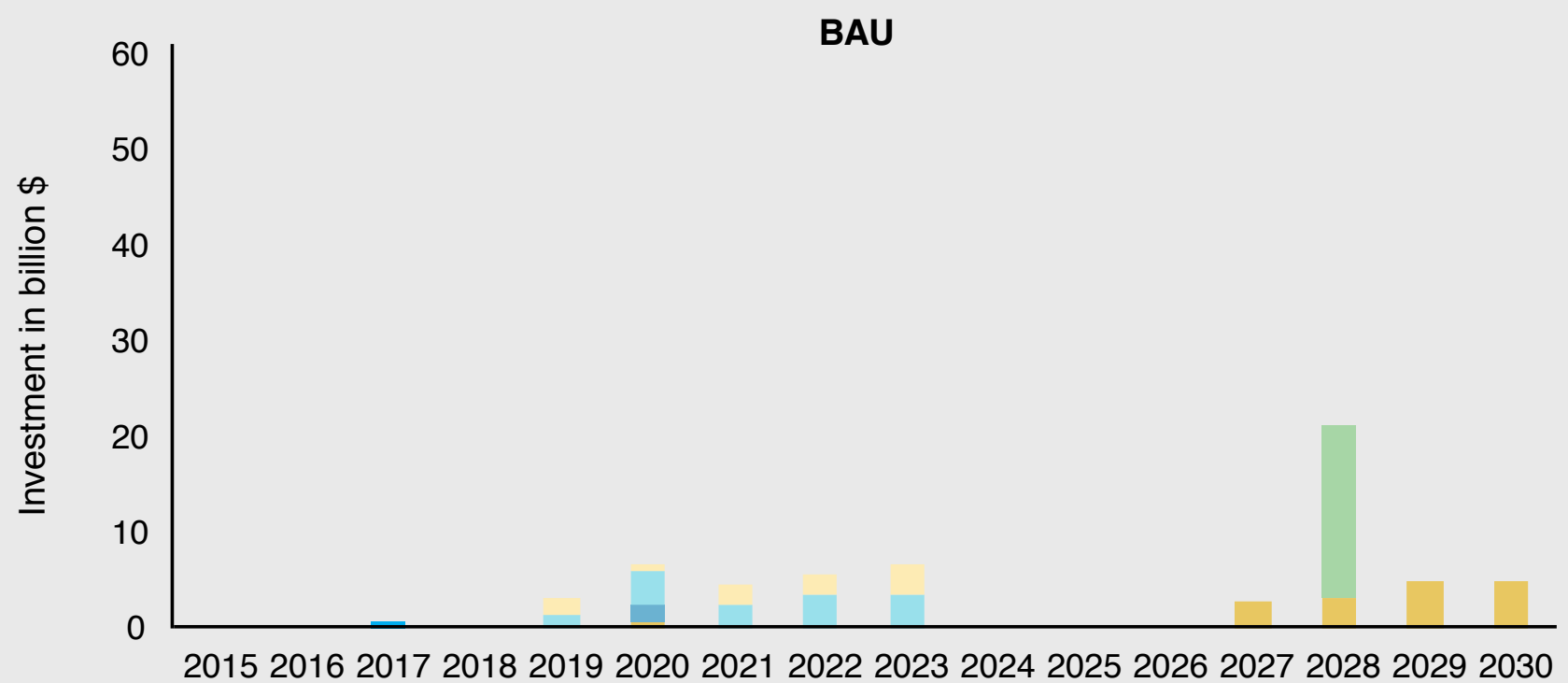

$\square$ CCGT $\square$ CSP $\square$ Cogen $\square$ GT $\square$ Nuclear $\square$ PV $\square$ Wind $\square$ Steam

PS

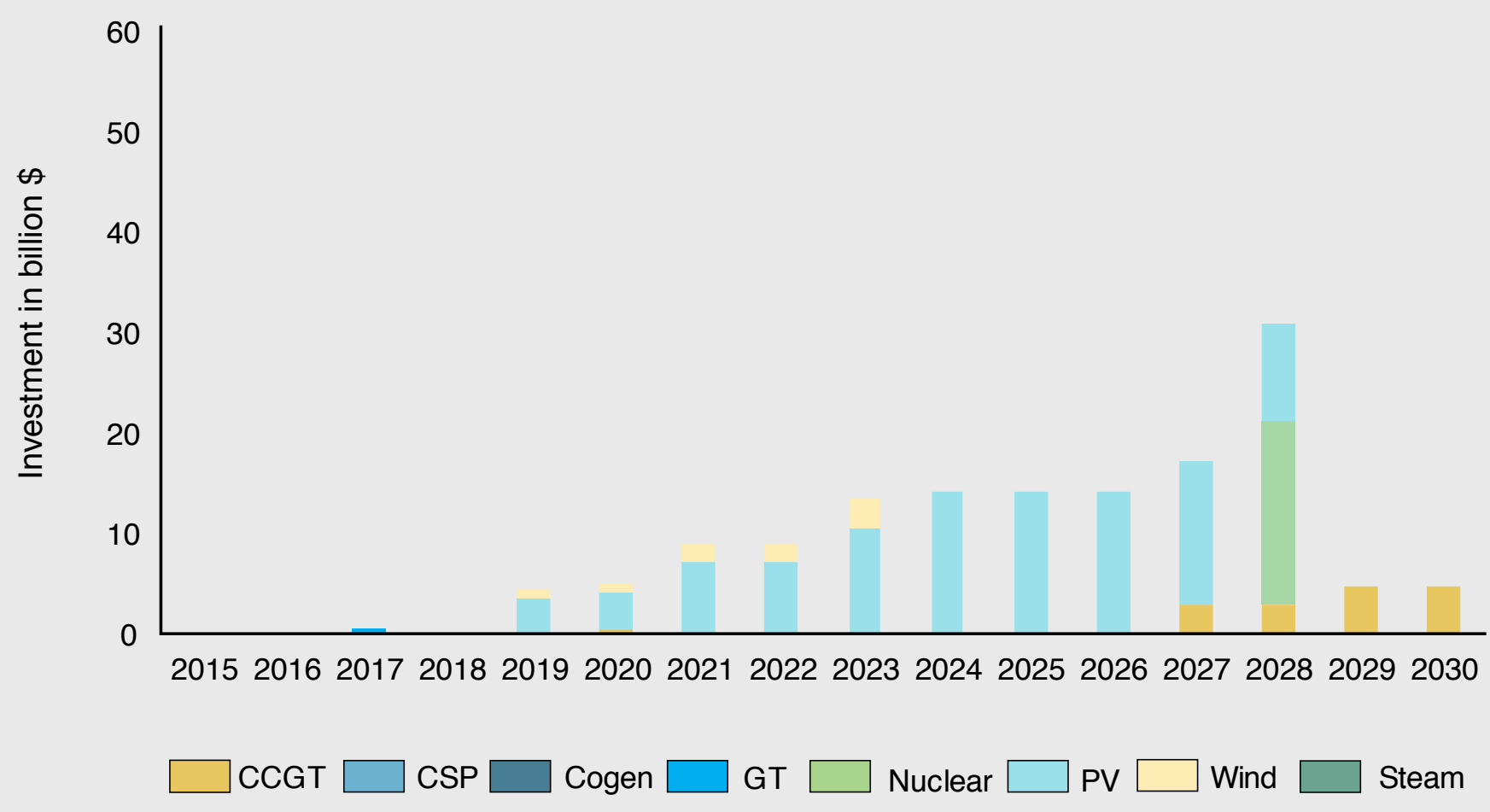



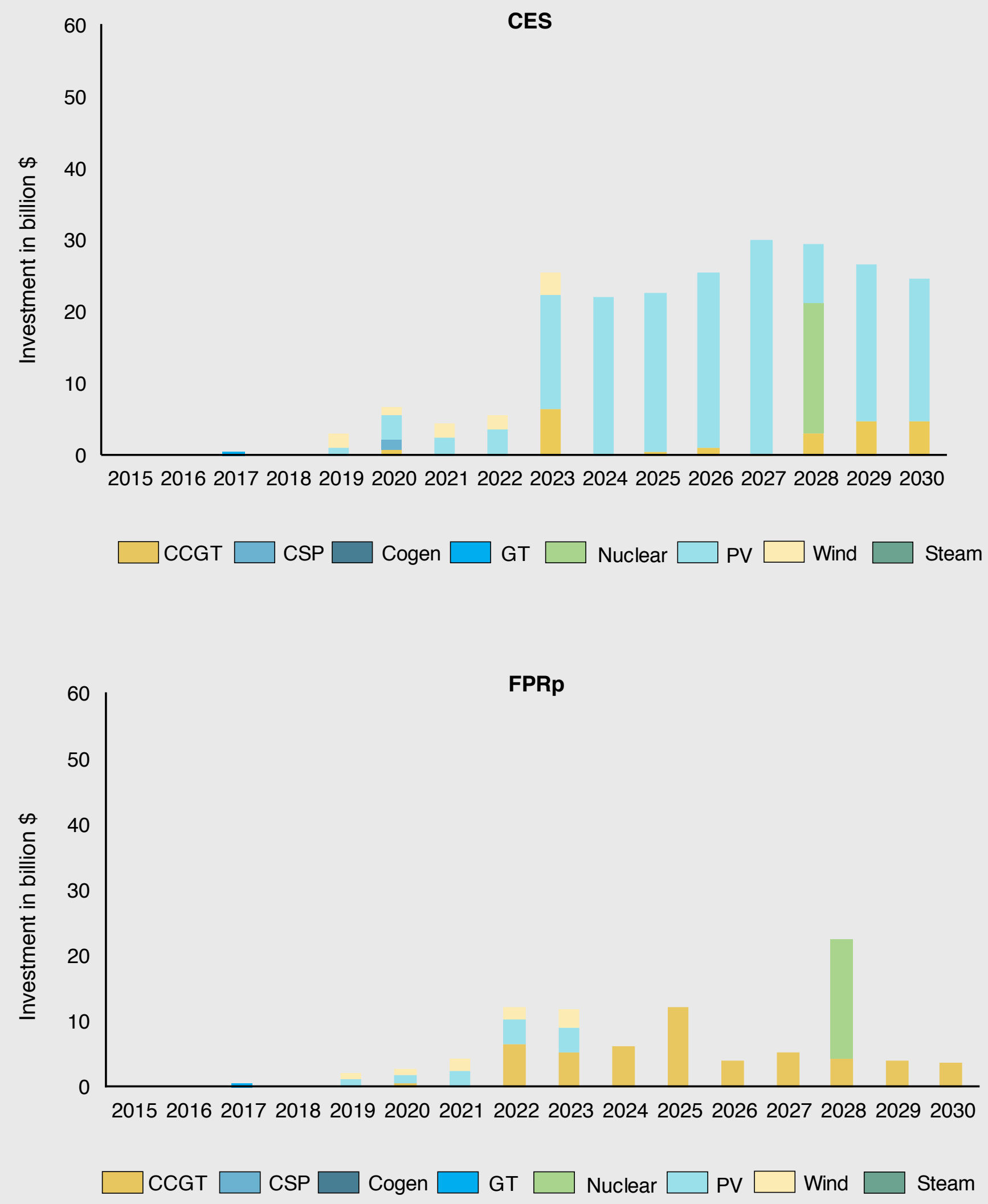


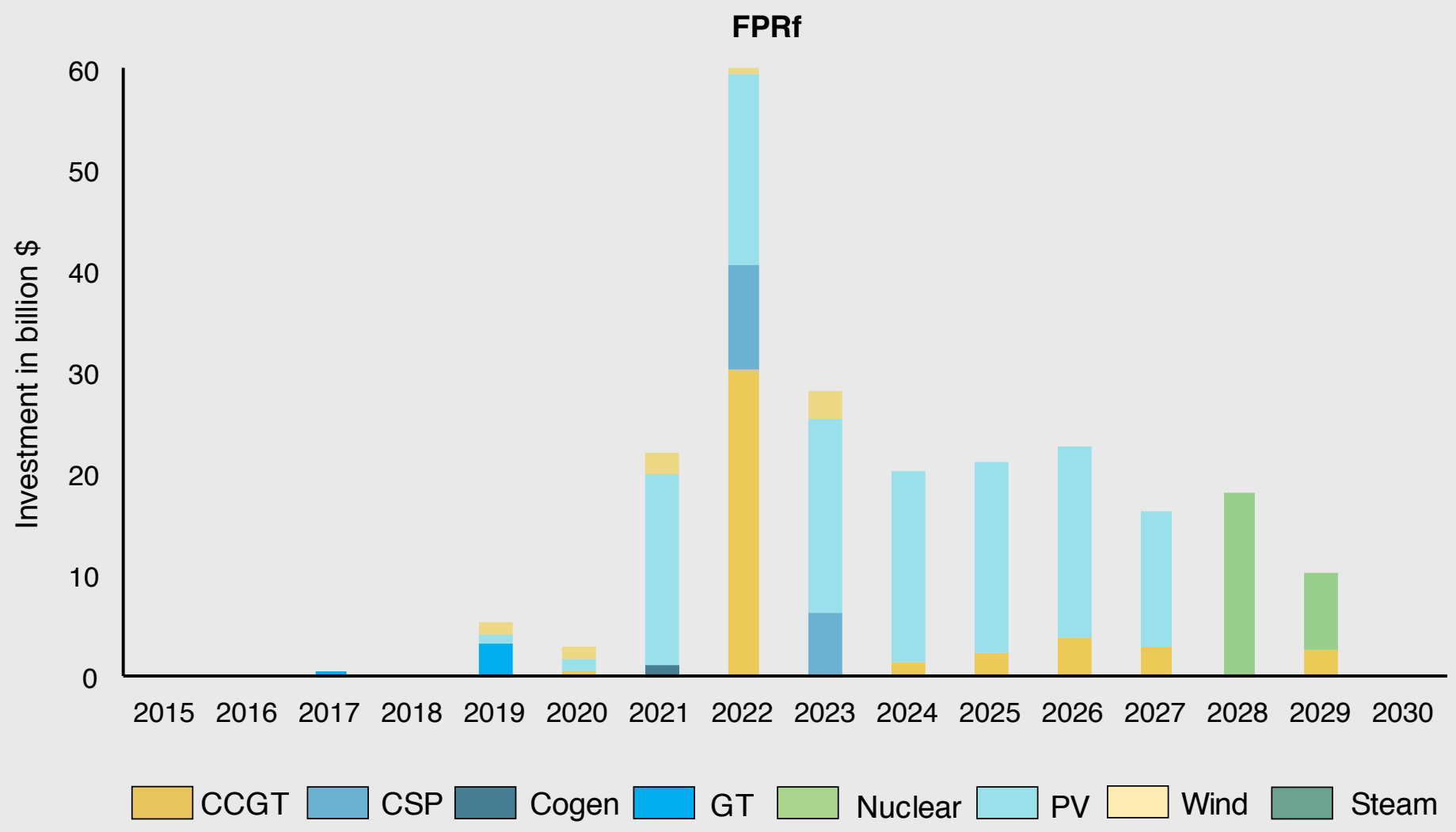

Source: KAPSARC analysis.

Figure 10. Annual capacity deployment by technology in GW.

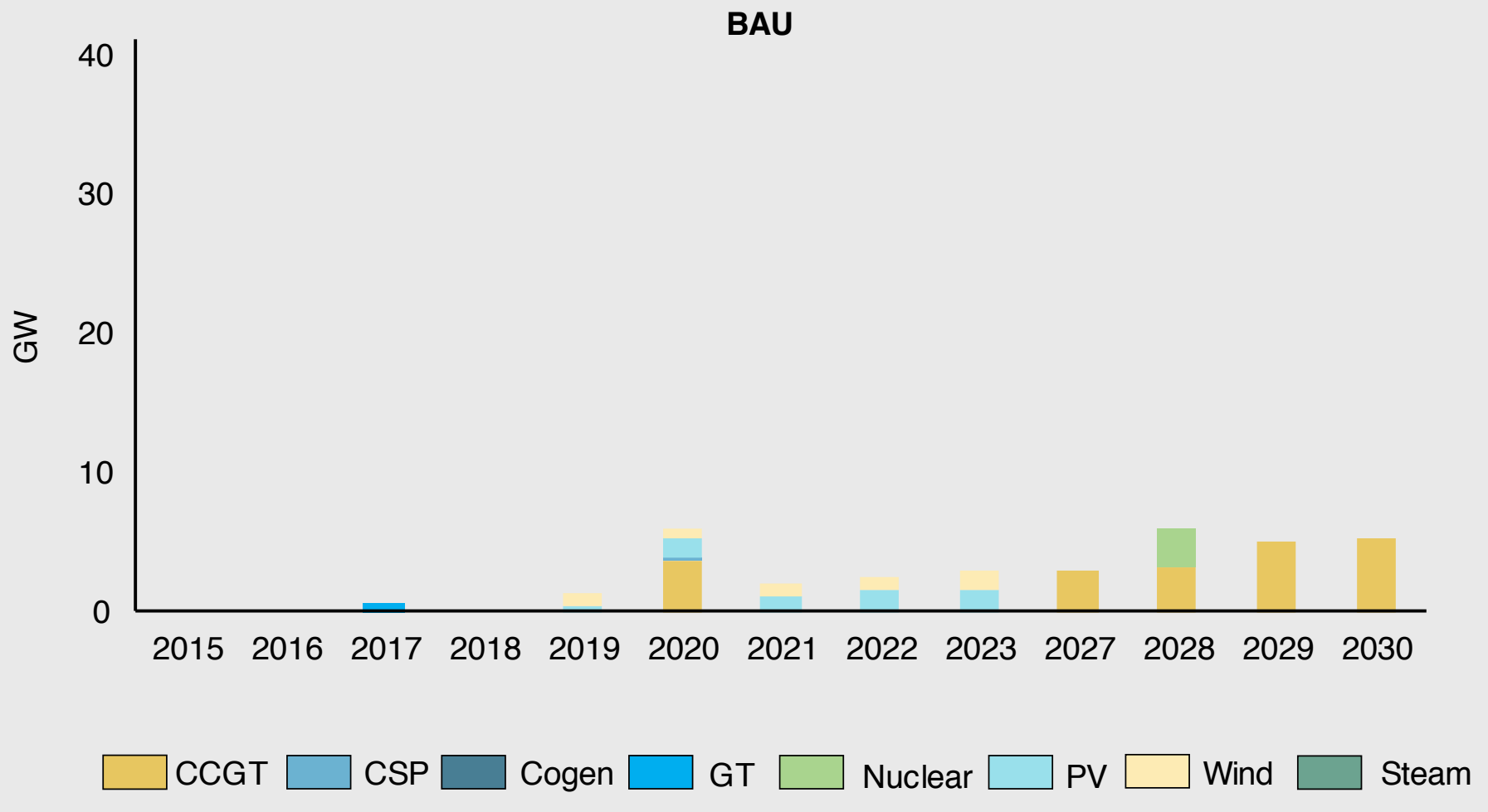



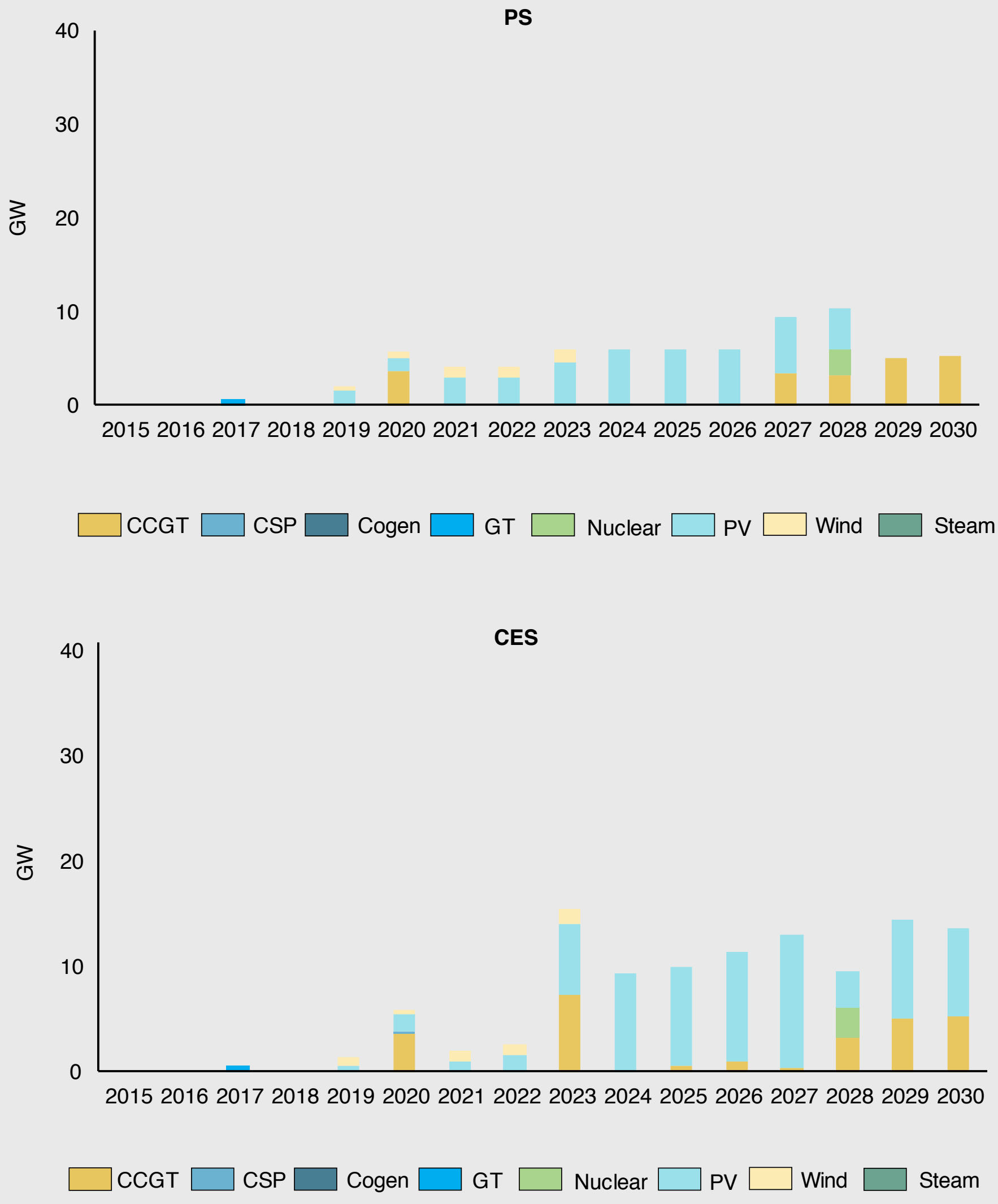

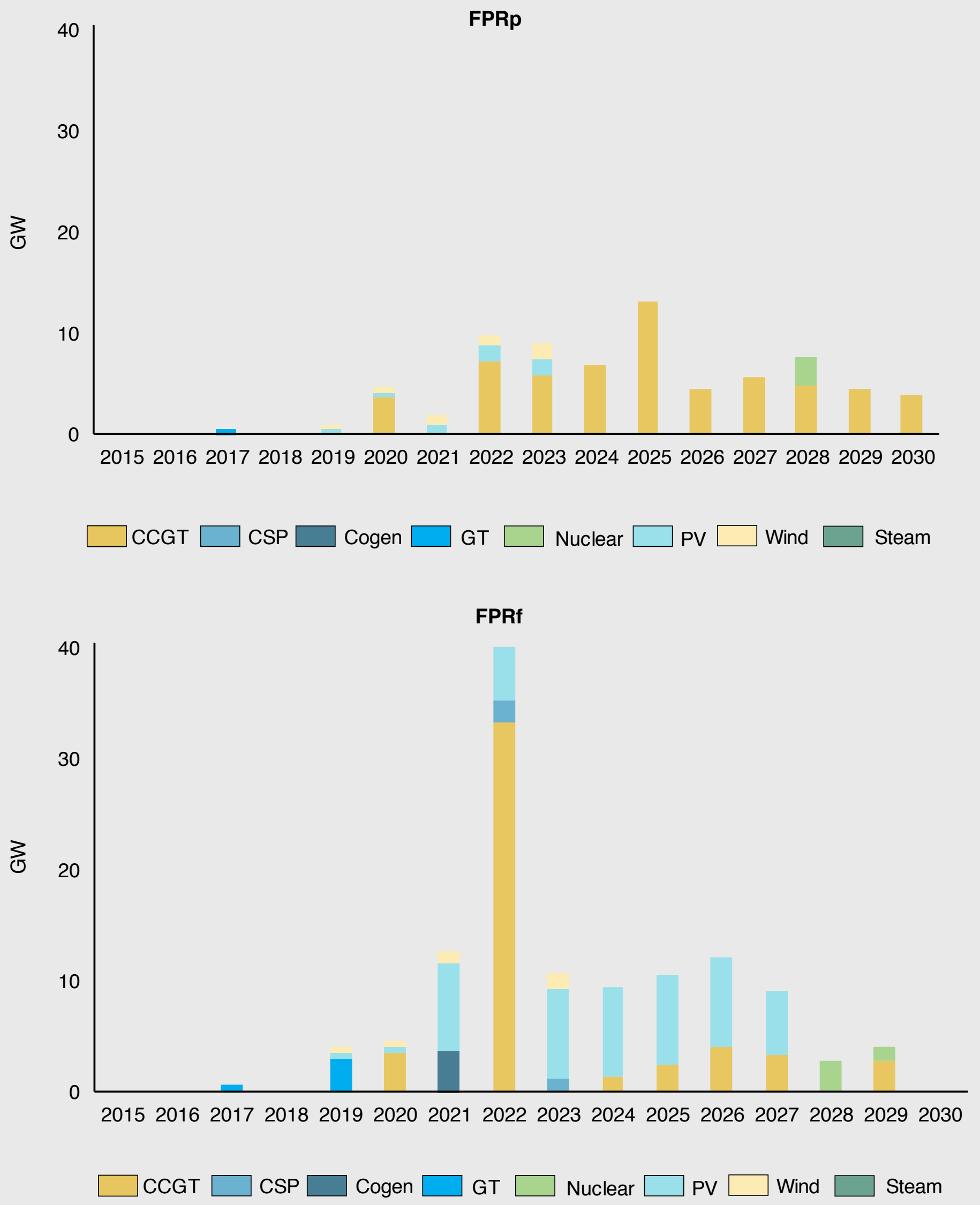

Source: KAPSARC analysis. 


\section{About the Authors}

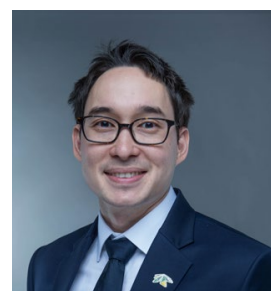

\section{David Wogan}

David is a former research associate at KAPSARC. His research centers on modeling the economics of integrated energy systems, with a focus on Saudi Arabia and the surrounding Gulf countries. David holds an M.Sc. in Mechanical Engineering and an M.A. in Public Affairs from the University of Texas in Austin.

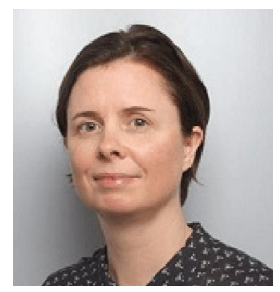

\section{Elizabeth Carey}

Elizabeth is a senior research associate at KAPSARC. Her research focuses on the UNFCCC and climate change policy. Elizabeth holds a P.hD. in Political Science - International Relations from Université Paris II Panthéon-Assas, an M.Sc. in Political Science from MIT, and a B.A. in Modern History from Oxford University.

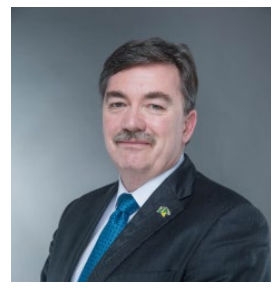

\section{Douglas Cooke}

Douglas is the former program director of the Energy Transitions and Environment program at KAPSARC. He is an experienced senior public policy practitioner with three decades of experience advising the Australian government.

\section{About the Project}

This study was developed in the context of Saudi Arabia's submission of its nationally determined contributions (NDCs) under the Paris Agreement on climate change. It evaluates three broad policy approaches to mitigate $\mathrm{CO}_{2}$ emissions from the power and water sectors through to 2030: a portfolio standard, a clean energy standard, and fuel price reforms. These three alternative policy approaches were assessed against a baseline of continuing existing policies set out in the business-as-usual (BAU) scenario. Each of these approaches was evaluated in terms of its practical implications for carbon emissions, electricity production, fuel consumption, investments and cost-effectiveness, as well as oil exports and revenues. The purpose of the study is to support the policymaking process as the Kingdom develops its future NDCs under the Paris Agreement. 
INAPSARC

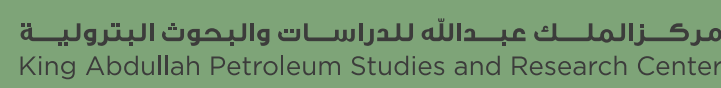

www.kapsarc.org 